\title{
Recent Advances in Carbon Nanotube-Polymer Composites
}

\author{
Junjie Chen", Longfei Yan \\ Department of Energy and Power Engineering, Henan Polytechnic University, Jiaozuo, China
}

Email address:

hantpj@163.com (Junjie Chen)

*Corresponding author

\section{To cite this article:}

Junjie Chen, Longfei Yan. Recent Advances in Carbon Nanotube-Polymer Composites. Advances in Materials.

Vol. 6, No. 6, 2017, pp. 129-148. doi: 10.11648/j.am.20170606.14

Received: September 24, 2017; Accepted: October 24, 2017; Published: November 24, 2017

\begin{abstract}
Carbon nanotubes demonstrate remarkable mechanical, thermal, and electrical properties, which allow a number of exciting potential applications. In this article, the most recent progress in research on the development of carbon nanotube-polymer composites is critically reviewed, with emphasis on recent advances in the principles and techniques for carbon nanotube functionalization. Various functionalization approaches and their role in the preparation of carbon nanotube-polymer composites with improved mechanical and electrical properties are discussed. The interaction between carbon nanotubes and polymers is also reviewed. Various techniques of carbon nanotube-polymer interaction measurements, including experimental and modelling studies, are described. Different methods of interaction improvement, mainly categorized under covalent and noncovalent interactions, are also described afterwards. An optimum carbon nanotube-polymer interaction is a crucial factor towards reaching the full potential of carbon nanotubes in nanocomposites. Potential topics of oncoming focus along with the potential applications of carbon nanotube-polymer composites are highlighted.
\end{abstract}

Keywords: Nanocomposites, Polymer Composites, Carbon Nanotubes, Physical Properties, Dispersion, Reinforcement, Functionalization, Interaction

\section{Introduction}

Carbon nanotubes were first observed by Iijima $[1,2]$, almost two decades ago, and since then, extensive work has been carried out to characterize their properties [3, 4]. Carbon nanotubes themselves have remarkable electrical, thermal, and mechanical properties. For example, carbon nanotubes theoretically have exceptional mechanical properties such as elastic modulus and strengths 10-100 times higher than the strongest steel at a fraction of the weight. Outstanding electrical, thermal, and mechanical properties of carbon nanotubes makes them a promising candidate for a wide variety of applications [1-4]. Carbon nanotubes have the potential to impact a wide range of fields and thus have emerged as one of the most promising materials in nanoscience research. Structural nanocomposites, in particular, aimed for taking advantage of the superior mechanical properties of carbon nanotubes as well as their high aspect ratios and surface areas [5-8]. In recent years, carbon nanotubes are prime candidates for use in the development of polymer composite materials [5-12]. Considerable efforts have been devoted to fabricate advanced carbon nanotube composite materials that exhibit one or more of the above-mentioned excellent properties [13-22]. The combination of remarkable properties makes carbon nanotubes potentially ideal candidates for the formation of polymer composites with improved mechanical properties and electrical conductivity [23-28]. Carbon nanotubes can be thought of as the ultimate carbon fiber with break strengths reported as high as $200 \mathrm{GPa}$, and elastic moduli in the 1000 Gpa range [29-32]. This, coupled with approximately 500 times more surface area per gram and aspect ratios of around 1000 , has spurred a great deal of interest in using carbon nanotubes as a reinforcing phase for polymer matrices.

Carbon nanotube-polymer nanocomposites have the advantage of size compatibility between their constituents [9-12]. Introducing carbon nanotubes to polymer matrices modifies electrical, thermal, mechanical, and morphological properties of the produced nanocomposite [13-22]. In order to obtain the best performance from carbon nanotube-polymer nanocomposites, there are a lot of technical challenges to overcome. For example, purification of carbon nanotubes is a 
necessary step to remove metallic and amorphous carbon impurities, while avoiding serious damage to the carbon nanotubes [13-15]. Furthermore, carbon nanotube content and alignment as well as the void content in the nanocomposite should be controlled [16-22]. The dispersion of carbon nanotubes in the polymer matrix plays an important role in the performance of nanocomposites. In general, it is a challenge to obtain the optimum dispersion, which requires further researches and exploration at different scales, particularly for nanocomposites with relatively high carbon nanotube content $[35,36]$.

Lacking direct manipulation, when used as reinforcement in polymers, carbon nanotubes are typically first randomly dispersed in a solvent or polymer fluid, melt by sonication or shear mixing followed by further processing to create the nanocomposite. The energy input to disperse the carbon nanotubes tends to break them into shorter segments [35, 36], decreasing their aspect ratio in the final composite while simultaneously increasing their dispersibility. However, insufficient dispersion is often cited as a process limitation [37] and the key diminishing factor $[33,38]$ on the mechanical properties of nanocomposite. Efforts to improve carbon nanotube dispersion include the use of surfactants [39, 40], as well as the oxidation or chemical functionalization of the surface of carbon nanotubes [11, 18, 35, 36].

Adding carbon-based fillers to polymers to improve mechanical properties, reduce weight, and act as heat conductors is not a novel idea. Carbon black has been widely utilized to reinforce rubber and plastics, for example, it is extensively used in racing tires to reduce thermal damage. Carbon fibers are also hugely popular industrial materials that are used in cars, airplanes, bicycles, etc. However, the carbon-based polymer additives with the greatest potential are carbon nanotubes. The ability to harness the mechanical strengths of carbon nanotubes has already given rise to new industrial products [3-8]. For example, sports equipment, such as tennis racquets and golf clubs containing carbon nanotubes, has been produced and marketed. With carbon nanotubes becoming easier to produce and cheaper to buy, the carbon nanotube industry could potentially overtake the carbon fiber industry and becomes one of the major additives for polymer-composite fabrication $[22,32]$.

There are a lot of studies and a limited number of literature reviews on the conductive and mechanical properties of carbon nanotube-polymer composites [6-8, 19, 21, 32, 36]. However, a significant progress has been made in the area of the preparation and utilization of carbon nanotube-polymer composite materials lately. In this article, the most recent progress in research on the development of carbon nanotube-polymer composites is critically reviewed, with emphasis on recent advances in the principles and techniques for carbon nanotube functionalization.

\section{Carbon Nanotube Materials and Properties}

Since the discovery of single-walled carbon nanotubes [2, 41], there has been a flurry of research activity aimed at understanding their physical properties [42], elucidating their growth mechanisms [43], and developing novel applications for them [44]. Carbon nanotubes and related nanomaterials along with their physical properties have been discussed extensively in the literature [1-8]. Consequently, a comprehensive review of this topic will not be presented here. A brief discussion of these nanomaterials and their physical properties is appropriate, however, to familiarize the reader with the typical characteristics and the most common methods of production.

There are three common types of carbon nanotube raw materials that can be employed as composite materials. These are single-walled carbon nanotubes $[2,16,23,24,26,35,41]$, multi-walled carbon nanotubes [1, 11, 26, 27, 31, 32], and carbon nanofibers [18, 22, 37]. The three raw materials can also be used in combination to develop composite materials. The morphologies of these nanomaterials are illustrated in Figure 1. These carbon nanotubes and carbon nanofibers are commercially available. A summary of the characteristics of each of these nanomaterials has been given in the literature [22]. Carbon nanotube properties have also discussed in the literature $[45,46]$.
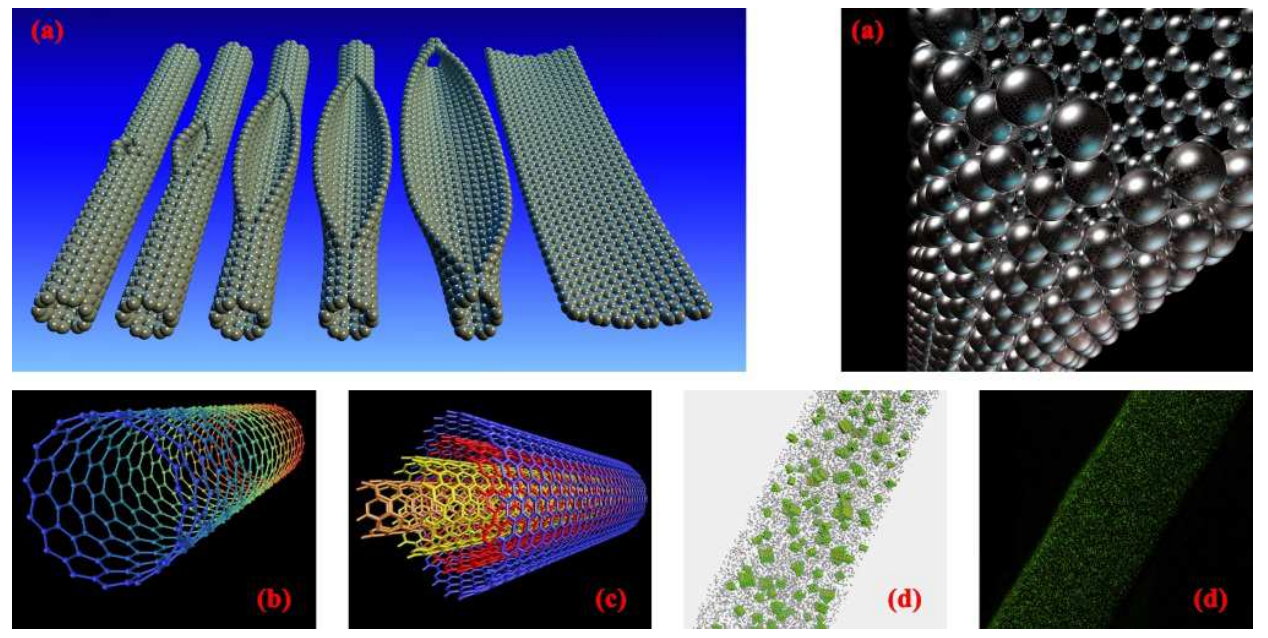

Figure 1. Schematic illustration of carbon nanotubes: (a) carbon nano-walls, (b) single-walled carbon nanotubes, (c) multi-wall carbon nanotubes, and (d) carbon nanofibers. 
Carbon nanotubes are the strongest and stiffest materials yet discovered [29-32]. This strength results from the covalent $\mathrm{sp}^{2}$ bonds formed between the individual carbon atoms. Although the strength of individual carbon nanotube shells is extremely high, weak shear interactions between adjacent shells and tubes result in a significant reduction in effective strength [47] The electronic property of carbon nanotubes is a strong function of its chemical doping, mechanical deformation, and atomic structure. Changing these properties can induce strong changes in electrical conductance [48]. The electrical impedance has been found to be very sensitive to chemical exposure $[49,50]$ and mechanical deformation [51]. These properties are highly dependent on the type of carbon nanotubes [52, 53]. Carbon nanotubes have useful absorption, photoluminescence, and Raman spectroscopy properties [54]. Spectroscopic methods offer the possibility of quick and non-destructive characterization of relatively large amounts of carbon nanotubes. There is a strong demand for such characterization from the industrial point of view: numerous parameters of the carbon nanotube synthesis can be changed, unintentionally or intentionally, to alter the quality of carbon nanotubes [54].

Recently, several kinds of techniques have been developed to produce carbon nanotubes in sizable quantities, such as arc discharge, laser ablation, and chemical vapor deposition [3, 4]. Most of these processes take place in a vacuum or with process gases. The growth method of chemical vapor deposition is popular $[48,55]$. Controlled synthesis of carbon nanotubes opens up exciting opportunities in nanoscience and nanotechnology, including electrical, mechanical, and electromechanical properties and devices, chemical functionalization, surface chemistry and photochemistry, and molecular sensors [48].

\section{Carbon Nanotube Functionalization}

The nanocomposite performance strongly depends on the dispersion of carbon nanotubes in the polymer matrix and the interfacial interactions between them [5-8]. However, the reinforcing carbon nanotubes are inert and can interact with the surrounding polymer matrix mainly through van der Waals interactions, unable to provide an efficient load transfer across the interface [8-20]. Consequently, considerable efforts have been devoted to develop methods in order to modify surface properties of carbon nanotubes $[4,53,56,57]$. These methods can be conveniently divided into chemical functionalization and physical methods based on the interactions between the active molecules and carbon atoms on the carbon nanotubes [15]. Major principles of these methods along with their advantages and disadvantages have been summarized in the literature [36].

It is known that carbon nanotube solubility, dispersion, and stress transfer must all be maximized to obtain optimum performance. Unless the interface between carbon nanotube and polymer is carefully engineered, poor load transfer between carbon nanotubes, when in bundles, and between carbon nanotubes and surrounding polymer chains may result in interfacial slippage. Consequently, functionalization of carbon nanotubes is extremely important for their processing and potential applications in polymer composites [19]. In general, composites based on chemically modified carbon nanotubes show the best mechanical results because functionalization enables a significant improvement in both dispersion and stress-strain transfer. The treatment of carbon nanotubes by chemical functionalization is widely used to improve the dispersion of carbon nanotubes in solvents [19].

The functionalization of carbon nanotubes not only results in the improved dispersibility in various organic solvents and polymers [58], but also increases the interface strength [58]. However, chemical functionalization may disrupt the bonding of the graphene sheet, and thereby reduces the mechanical properties [5]. Several approaches have been developed, in both molecular and supramolecular chemistry [36]. These approaches include defect functionalization, covalent functionalization of the sidewalls, noncovalent exohedral functionalization, for example, formation of supramolecular adducts with surfactants or polymers, and endohedral functionalization, as illustrated in Figure 2. (b)

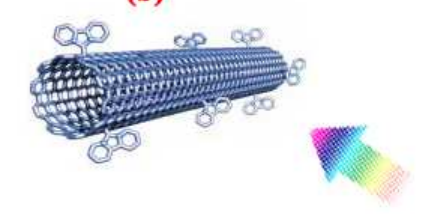

(a)

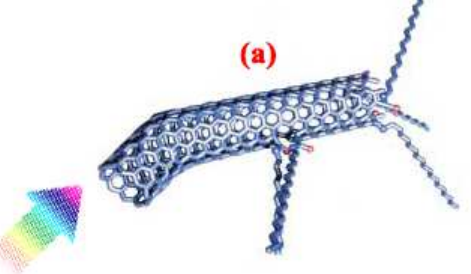

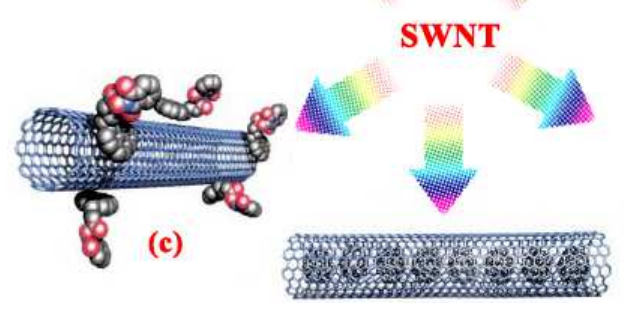

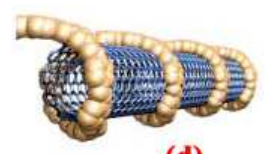

(d)

Figure 2. Functionalization possibilities for single-walled carbon nanotubes: (a) defect-group functionalization, (b) covalent sidewall functionalization, (c) noncovalent exohedral functionalization with surfactants, (d) noncovalent exohedral functionalization with polymers, and (e) endohedral functionalization with, for example, fullerenes. For methods (b)-(e), the carbon tubes are drawn in idealized fashion, but defects are found in real situations. 


\subsection{Chemical Functionalization}

Chemical functionalization is based on the covalent linkage of functional entities onto carbon scaffold of carbon nanotubes $[35,36]$. It can be performed at the termini of the carbon tubes or at their sidewalls. Direct covalent sidewall functionalization is associated with a change of hybridization from $\mathrm{sp}^{2}$ to $\mathrm{sp}^{3}$ and a simultaneous loss of $\pi$-conjugation system on the graphene layer. This process can be made by reaction with some molecules of a high chemical reactivity, such as fluorine [59-63]. Besides sidewall fluorination of carbon nanotubes, other similar methods, including cycloaddition, such as carbene and nitrene addition [64-66], Diels-Alder reaction, bromination [67], hydrogenation [68], chlorination, and aminobenzene acids [69], have also been successfully employed in recent years. All these methods can be regarded as the derivative of sidewall functionalization [36].

Defect functionalization is another method for the covalent functionalization $[35,36,56,57]$. This process takes advantage of chemical transformation of defect sites on carbon nanotubes. Defect sites can be the open ends and holes in the sidewalls, pentagon or heptagon irregularities in the hexagon graphene framework. Oxygenated sites can also to be considered as defects [36]. Defects can be created on the sidewalls as well as at the open ends of carbon nanotubes by an oxidative process with strong acids such as nitric acid, sulfuric acid, a mixture of them [70,71], or with strong oxidants [72-75]. The defects on carbon nanotubes created by oxidants are stabilized by bonding with carboxylic acid or hydroxyl groups. These functional groups have rich chemistry and the carbon nanotubes can be used as precursors for further chemical reactions, such as silanation [76], polymer grafting
[77], esterification [78], thiolation [79], and alkylation and arylation $[80,81]$. The carbon nanotubes functionalized in this way are soluble in many organic solvents because the hydrophobic nature of carbon nanotubes is changed to hydrophilic one due to the attachment of polar groups. The chemically functionalized carbon nanotubes can produce strong interfacial bonds with many polymers, allowing carbon nanotube-based nanocomposites to possess high mechanical and functional properties [36].

\subsection{Physical Functionalization}

Functionalization of carbon nanotubes using a covalent method can provide useful functional groups onto the surface of carbon nanotubes [36]. Unfortunately, these methods have two major drawbacks: firstly, during the functionalization reaction, a large number of defects are inevitably created on the sidewalls of carbon nanotubes, and in extreme cases, carbon nanotubes are fragmented into smaller pieces [36]. These damaging effects can result in severe degradation in mechanical properties of carbon nanotubes as well as disruption of $\pi$ electron system in carbon nanotubes. The disruption of $\pi$ electrons is detrimental to transport properties of carbon nanotubes because defect sites scatter electrons and phonons that are responsible for the thermal and electrical conductions of carbon nanotubes, respectively. Secondly, strong oxidants or concentrated acids are usually used for the functionalization of carbon nanotubes, which are typically environmentally unfriendly [36]. Consequently, considerable efforts have been devoted to develop methods that are of low cost, less damage to the structure of carbon nanotubes, and convenient to use.
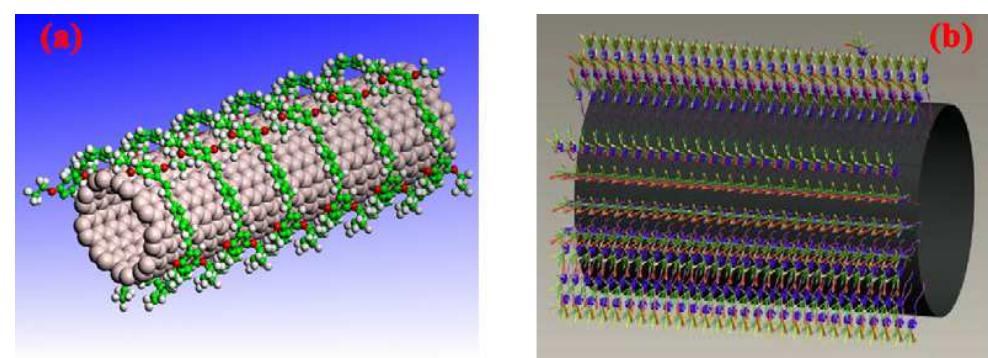

Figure 3. Schematic illustration of carbon nanotube functionalization using non-covalent methods: (a) polymer wrapping, (b) surfactant adsorption, and (c) endohedral method.

Non-covalent functionalization is an alternative method for tuning the interfacial properties of carbon nanotubes. The functionalization of carbon nanotubes using non-covalent methods is illustrated in Figure 3. The suspension of carbon nanotubes in the presence of polymers, such as polyphenylene vinylene [82] or polystyrene [83], results in the wrapping of polymer around the carbon nanotubes to form supermolecular complexes of carbon nanotubes, as shown in Figure 3(a). This is a typical example of non-covalent functionalization of carbon nanotubes. The polymer wrapping process is achieved through the van der Waals interactions and $\pi-\pi$ stacking between carbon nanotubes and polymer chains containing aromatic rings.

Surfactants have also been employed to functionalize carbon nanotubes, as shown in Figure 3(b). Several studies have been contributed to the in-depth study of the effects of surfactant on dispersibility and other physical properties of carbon nanotubes. The surfactants studied previously include non-ionic surfactants $[84,85]$, anionic surfactants $[86,87]$, and cationic surfactants $[88,89]$. A simulation showing single-walled carbon nanotubes embedded within sodium dodecyl sulfate micelles is illustrated in Figure 4. In particular, a recent work provides a comprehensive review of the mechanisms behind the improved dispersibility of carbon nanotubes [90]. The physical adsorption of surfactant on the surface of carbon nanotubes lowered the surface tension of carbon nanotubes, effectively preventing the formation of 
aggregates. Furthermore, the surfactant-treated carbon nanotubes overcomed the van der Waals attraction by electrostatic-steric repulsive forces. The efficiency of this method was highly dependent on the properties of medium chemistry, surfactants, and polymer matrix. In water-soluble polymers such as polyethylene glycol, cationic surfactants had some advantages, whereas in water-insoluble polymers, the dispersion of carbon nanotubes was promoted by a non-ionic surfactant $[39,90,91]$. The treatment of non-ionic surfactants was based on a strong hydrophobic attraction between the solid surface and the tail group of surfactant. Once the surfactant was adsorbed onto the surface of the filler, the surfactant molecules were self-assembled into micelles above a critical micelle concentration [36].
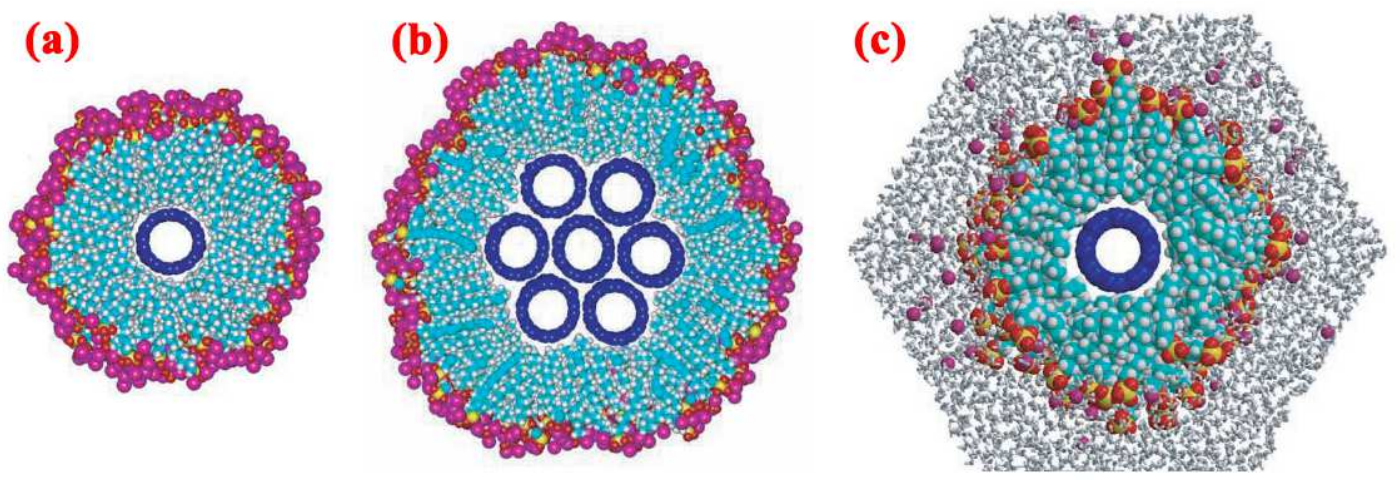

Figure 4. A simulation showing single-walled carbon nanotubes embedded within sodium dodecyl sulfate micelles: (a) an individual single-walled carbon nanotube embedded in a cylindrical sodium dodecyl sulfate micelle, (b) a seven-tube bundle of single-walled carbon nanotubes coated by a layer of sodium dodecyl sulfate, and (c) a larger region showing a water-free hydrocarbon environment as well. Adapted with permission from Ref. [86].

Another non-covalent method is the endohedral method, as shown in Figure 3(c). In this method, guest molecules or atoms are stored in the inner cavity of carbon nanotubes through the capillary effect. The insertion often takes place at defect sites localized at the ends or on the sidewalls of carbon nanotubes. The insertion of inorganic nanoparticles into the carbon nanotubes [92] is a typical example of endohedral functionalization. Small biomolecules can also be entrapped in the inner hollow channel of carbon nanotubes by simple adsorption, forming natural nano-test tubes [56, 93]. The combination of these two materials is particularly useful to integrate the properties of the two components in hybrid materials for use in energy storage, catalysis, nanotechnology, and molecular scale devices [92].

\section{Carbon Nanotube-Polymer Interfaces}

Particular attention is focused on the carbon nanotube-polymer interface [94-100]. From micro-mechanics, it is through shear stress build-up at this interface that stress is transferred from the polymer matrix to the carbon nanotubes [5, 8-20]. Lower-than-predicted carbon nanotube-polymer composite properties can be attributed to a lack of interfacial bonding [101, 102]. If the surface of a carbon nanotube, essentially an exposed graphene sheet, is considered, it is not surprising that interfacial traction is a concern [5]. It is the weak inter-planar interaction of graphite that provides its solid lubricant quality, and resistance to polymer matrix adhesion. This is exaggerated by the chemically inert nature of graphene structures [5]. A June 2002 publication on carbon nanotube composites noted "In depth study on the stress transfer mechanism of the carbon nanotube composites with different chemical and geometrical properties, matrix environments and loading conditions are essential" [103]. Since then, some interesting published results have described progress on addressing this issue. The force required to separate a carbon nanotube from a solid polymer matrix has been measured by performing reproducible nanopullout experiments using atomic force microscopy [104]. The computed average interfacial shear strength using a Kelly-Tyson approach of 47 $\mathrm{MPa}$, typical values for carbon fiber-epoxy are in the range of 30 to $80 \mathrm{MPa}$ [105], was sufficiently high to suggest that covalent bonding between defects in the outer shell of the carbon nanotube and the polymer was occurring. It also suggested that the polymer chains close to the interface behaved differently than the bulk, a logical result when considering the outer diameter of the carbon nanotubes was of similar magnitude to the radius of gyration for the polymer. In a report corroborating an interfacial region of non-bulk polymer, a "sheathing layer" of polycarbonate on pulled out multi-walled carbon nanotubes was imaged, which gave further direct evidence of substantial carbon nanotube-polymer interaction [106]. Furthermore, chemical functionalization of the carbon nanotubes augmented the diameter of the polymer sheath suggesting chemical augmentation of interfacial bonding. Acid oxidation of multi-walled carbon nanotubes was again reported to attach carboxylic groups on the surface, which were then reacted with epoxide-terminated molecules up to 12 weight percent by a method of thermal gravimetric analysis [58]. These types of functionalized carbon tubes could enhance reinforcement of epoxy resins. Carboxylated tubes have also been reported to augment the cure rate of epoxy resins at lower operating temperatures [107]. Unfortunately, direct and indirect measurement of carbon nanotube-polymer interfacial shear strength suggesting good bonding exists conflict with other reports which often cite clean pull-out of carbon nanotubes and poor interfacial bonding $[101,108]$. The magnitude of 
carbon nanotube strength, more than 10 times that of typical carbon fiber, may preclude embedded carbon nanotube tensile failure in large numbers resulting in the dominant failure mode to be carbon nanotube pull-out. Order of magnitude increases in interfacial shear strength may be required for the most efficient strengthening of polymers with carbon nanotubes. Optimizing the carbon nanotube-polymer interface for nanoscale mechanical reinforcement remains unclear, but the evidence available indicates that chemical means can be effective, and this is likely to be a major focus in the near term.

Theoretical treatments of carbon nanotube pull-out have also been reported in the literature [108, 109]. A single-walled carbon nanotube pulled out from a crystalline polyethylene matrix, which interacted with the carbon nanotube through van der Waals forces represented by the Lennard-Jones potential, was modeled through molecular dynamics simulations and described by an interfacial friction model. The velocities and displacements of carbon nanotubes were traced in order to characterize the interfacial interactions during carbon nanotube pull-out. The interfacial friction between carbon nanotube and polymer was described with a relation between the applied force and carbon nanotube velocity. Furthermore, an interfacial friction model for the entire pull-out process was proposed, which involved an effective viscosity coefficient for the interfacial sliding. The existence of a carbon-ring-based period in carbon nanotube sliding during pull-out was identified. Linear trends in the carbon nanotube velocity-force relation were observed and used to estimate an effective viscosity coefficient for interfacial sliding at the carbon nanotube-polymer interface. A low effective viscosity of $0.2 \mathrm{cP}$ was found for interfacial sliding [108]. A force of approximately $0.1 \mathrm{nN}$ was required for pull-out to initiate for a carbon nanotube.
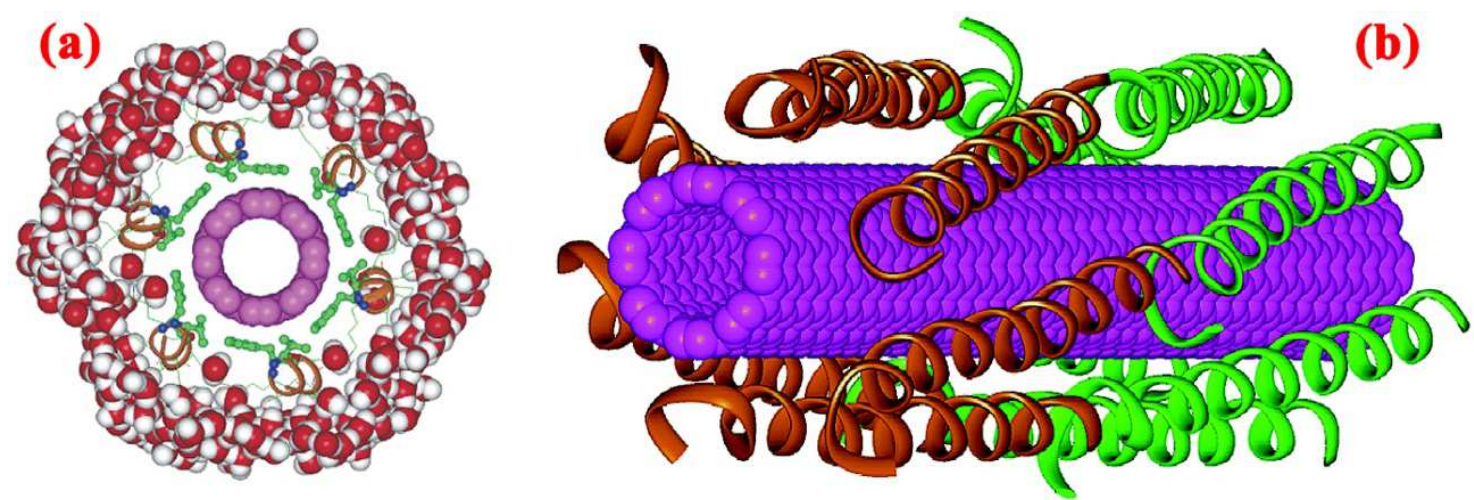

Figure 5. A model illustrating potential interactions between a synthetic, hydrophilic polypeptide and an individual single-walled carbon nanotube: (a) cross-section view of a carbon nanotube wrapped by six peptide helices and a water shell, and (b) view of a peptide-wrapped carbon nanotube illustrating the 12 peptide helices used in the model. Adapted with permission from Ref. [129]. For interpretation of the references to color in this figure legend, the reader is referred to the web version of this article.

Strong binding and carbon nanotube-polymer-wrapping were also reported for biopolymers. Interactions between specific types of deoxyribonucleic acid and carbon nanotube enabled the visualization of deoxyribonucleic acid [120] and affected the properties of carbon nanotubes [121]. Carbon nanotube-deoxyribonucleic acid complexes were found to form stable dispersions [122], enable fractionation of carbon

\section{Strongly Coupled Carbon Nanotube-Polymer Systems}

Strong coupling has been reported in conducting carbon nanotube-polymer systems [8-20]. The conduction mechanism of polymers is based on the motion of charged defects within the conjugated framework, and strongly depends on the level of doping [110-112]. Conducting polymers have been successfully utilized for commercial applications. Recently, considerable efforts have been devoted to optimization of the optical and electrical properties of conducting polymers, mainly via the development of efficient pathways for doping [110]. Recent experiments have demonstrated that multi-walled carbon nanotubes could be used for doping of a functional conjugated polymer [113], polyaniline [114], and a conjugated luminescent polymer. The electronic structure of functional conjugated polymer [115] as well as other types of conducting polymers was modified by the presence of carbon nanotubes [116, 117], indicating strong carbon nanotube-polymer coupling. In a different system [117], single-walled carbon nanotubes promoted the solution-protonation of the polymer, and thus affected its electrical properties. Conjugated polymers and carbon nanotubes were strongly associating, tightly bound systems [100]. The molecular geometry of the association was that of helical wrapping of the carbon nanotubes by the polymers [117]. The polymer-wrapped carbon nanotubes formed long-lived stable dispersions in different liquid media [118], and might be utilized for the preparation of carbon nanotube-polymer composites [119] exhibiting improved mechanical and electrical properties. 
that single-walled carbon nanotubes induce preferential folding of the peptide into specific configurations, and the interactions among the single-walled carbon nanotube-peptide moieties could be utilized for controlled self-assembly of the complexes. The concept is demonstrated in Figure 5. Electron microscopy and polarized Raman studies revealed that the peptide-coated carbon nanotubes assemble into fibers with the carbon nanotubes aligned along the fiber axis. Most importantly, the size and morphology of the fibers can be controlled by manipulating solution conditions that affect peptide-peptide interactions.

Dispersion of carbon nanotubes through polymer wrapping was suggested in additional systems, where it was conjectured that wrapping results in screening of the hydrophobic interaction at the carbon nanotube-water interface [130, 131]. This approach, wrapping water-soluble linear polymers around the carbon nanotubes, was robust and general, allowing pristine carbon nanotubes to be manipulated reliably by solution-phase techniques such as electrophoresis and chromatography, and simplifying their use as chemical reagents. The carbon nanotubes could be unwrapped by changing the solvent system. This solubilization process opens the door to solution chemistry on pristine carbon nanotubes [130].

\section{Carbon Nanotube-Polymer Interactions in Nanocomposites}

The carbon nanotube-polymer interfacial characteristics directly affect the efficiency of carbon nanotube reinforcements in improving mechanical, thermal, and electrical properties of the carbon nanotube-polymer nanocomposite [100]. An optimum carbon nanotube-polymer interaction is a critical factor towards reaching the full potential of carbon nanotubes in nanocomposites [100]. While a wide range of characteristic parameters has been reported, there are contradictory reports that show the effect of carbon nanotube on a particular property to be indifferent, improving, or even deteriorating [132]. These contradictory findings are perhaps obtained due primarily to differences between material characteristics and processing conditions of the nanocomposites. Furthermore, there are a number of other parameters such as the curvature of carbon nanotubes [133, 134], which has been found to play a significant role in achieving the optimum performance of nanocomposites. However, the experimental results or even realistic modelling predictions have always been below the rule of mixtures predictions [135]. The root cause of these under-performances may be sought in interaction behavior of the nanocomposite constituents. The interaction characteristics significantly affect the performance of nanocomposites. Furthermore, the answer to challenges, such as the dispersion of carbon nanotubes in nanocomposites, lies with the interaction characteristics of the system. Consequently, the interaction properties of the system should be tailored in order to optimize the performance of nanocomposites.

The carbon nanotube-polymer interaction characteristics have been studied at three different levels: between different shells of a multi-walled carbon nanotube [136], between different carbon nanotubes in a bundle [137], and between carbon nanotubes and the polymer matrix [138]. The first two types of carbon nanotube-polymer interaction are only related to the characteristics of carbon nanotubes. However, the carbon nanotube-polymer interaction is dependent on the characteristics of both constituents and how they interrelate with each other. The performance of conventional composites has also been found to be affected by fiber-matrix interaction [139]. However, there are fundamental differences in interaction characteristics between them, and a general overview of the interaction studies is missing in the literature. Consequently, a brief discussion of the interaction studies on carbon nanotube-polymer nanocomposites is given as follows.

\subsection{Noncovalent Interaction}

The extensive efforts to improve carbon nanotube-polymer interaction may be classified under noncovalent and covalent interaction categories [100]. The noncovalent interaction in polymer nanocomposites is enhanced by using any mechanical interaction improving techniques, including bridging, increasing specific interfacial area, and wrapping [100]. Bridging happens when a polymer chain interacts with two or more reinforcements at the same time. The possibility of bridging phenomenon is determined by the ratio of polymer radius of gyration to the average distance between nearest reinforcements [140]. Consequently, increasing the content of carbon nanotubes or using polymers with higher molecular weight greatly increases the chance of bridging. A specific interaction area is the polymer-reinforcement interfacial area per unit volume, only depending on the polymer to reinforcement density ratio as well as weight fraction and diameter of the reinforcement [140]. Consequently, increasing the content of properly dispersed carbon nanotubes enhances the specific interfacial area and results in a stronger nanocomposite [141]. The wrapping mechanism [142] not only results in a better carbon nanotube-polymer interaction but also helps to improve the dispersion of carbon nanotubes [143]. It is affected by the structure of the polymer, chemical composition of the polymer molecules, and geometric parameters of the constituents in the nanocomposite. Polymers with stiff backbones tend to wrap around carbon nanotube reinforcements with more distinct conformation [144], and form a helical configuration [145]. However, flexible polymer chains with bulky and aromatic side groups form an interchain coiling rather than a helical conformation [146]. Figure 6 shows examples of flexible and stiff backbone polymers interacting with single-walled carbon nanotubes. Chemical composition of the polymer also affects the wrapping behavior of the chains. On the other hand, bulky aliphatic side chains hinder such interactions. Finally, the geometric parameters of the polymer and reinforcement determine the possibility of wrapping. When the radius of gyration of the chains is greater than the radius of carbon nanotubes, there is a significant improvement in carbon nanotube-polymer interaction properties [140]. Consequently, nanocomposites with high 
molecular weight polymers and small diameter carbon nanotubes are more viable to present wrapping mechanism.
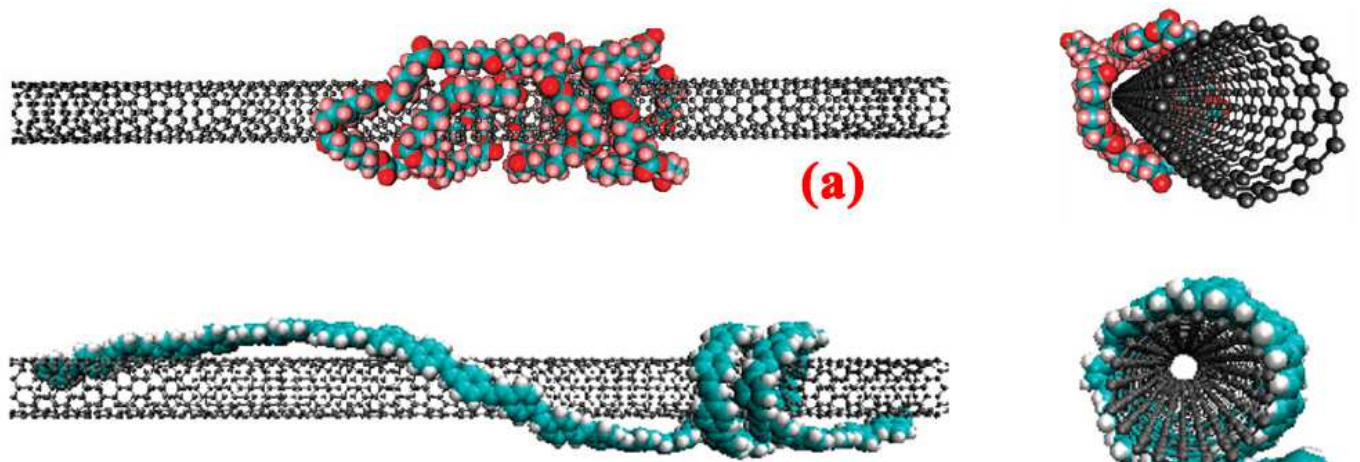

(b)

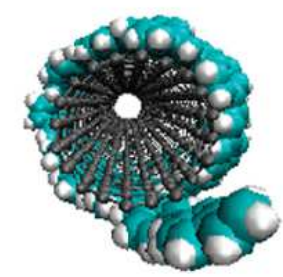

Figure 6. Molecular dynamics snapshots of polymer chains introduced to a single-walled carbon nanotube. Panel (a) shows poly(caprolactone) with flexible backbone interacting with the carbon nanotube at $3200 \mathrm{ps}$ [146]. Panel (b) shows poly(paraphenylene vinylene) with a stiff backbone interacting with the carbon nanotube at 2400 ps [144]. Adapted with permission from Refs. [144, 146]. For interpretation of the references to color in this figure legend, the reader is referred to the web version of this article.

Wang et al. [147] reported a simple and scalable method to enrich large quantities of semiconducting arc-discharged single-walled carbon nanotubes using dithiafulvalene-thiophene copolymers. Stable solutions of highly individualized and highly enriched semiconducting single-walled carbon nanotubes were obtained. Molecular dynamics simulations of polymer backbone interactions with and without side chains indicated that the presence of long alkyl side chains gave rise to the selectivity toward semiconducting tubes, indicating the importance of the roles

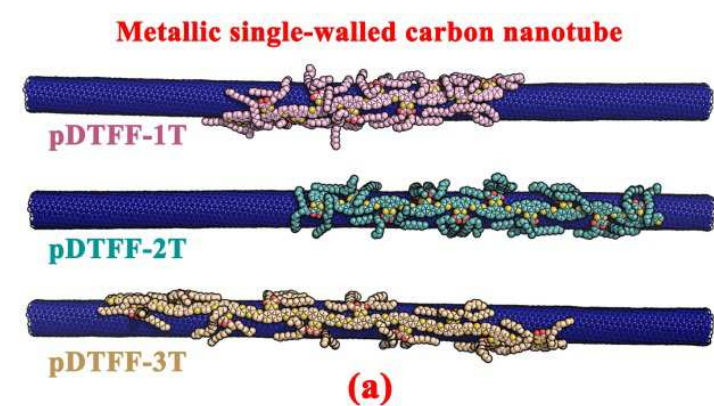

of the side chains to both solubilize and confer selectivity to the polymers. Representative snapshots of the molecular dynamics simulations are shown in Figure 7. Increasing the ratio of thiophene to dithiafulvalene units in the polymer backbone could slightly improve the selectivity toward semiconducting single-walled carbon nanotubes. High on to off ratio solution-processed thin film transistors were fabricated from the sorted single-walled carbon nanotubes to confirm the selective dispersion of semiconducting arc-discharge single-walled carbon nanotubes.

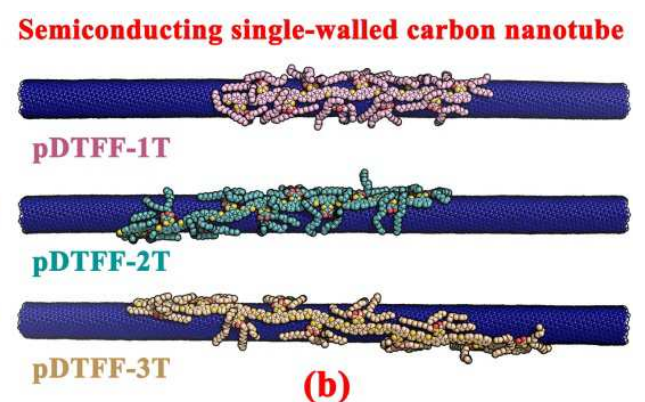

Figure 7. Representative snapshots of the molecular dynamics simulations for (a) a metallic single-walled carbon nanotube and (b) a semiconducting single-walled carbon nanotube with pDTFF-1T, pDTFF-2T, and pDTFF-3T. Adapted with permission from Ref. [147]. For interpretation of the references to color in this figure legend, the reader is referred to the web version of this article.

Noncovalent interaction methods require no extra preparation steps and induce no defect in the structure of the carbon nanotubes [100]. The interaction may significantly improve by in situ crystallization of the polymer with carbon nanotubes $[148,149]$. This type of interaction only provides a weak interfacial adhesion, depending on the polymer type. Furthermore, adjusting parameters such as carbon nanotube content and polymer molecular weight may affect the processability of the nanocomposite. One solution to address such problems is noncovalent grafting of carbon nanotubes with end-functionalized polymers [150]. In this technique, zwitterionic interactions or hydrogen bonds are formed between the defect sites of purified carbon nanotubes and the functional groups of the polymers [100]. Consequently, the undesirable defects caused by carbon nanotube purification play a positive role in this method, while the interactions are still noncovalent and the carbon nanotubes are not chemically functionalized by functional groups.

\subsection{Covalent Interaction}

The covalent interaction occurs when polymer chains are chemically bonded to the carbon nanotube reinforcements [100]. The covalent interaction has been found to be an effective method to improve nanocomposite properties $[151,152]$. It is typically achieved through open-end oxidation or sidewall functionalization [35]. Most of functionalization techniques require carbon nanotubes to be pre-modified by introducing functional groups to their surface. These functional groups 
should be compatible with the polymer matrix $[58,153,154]$ in order to react with reactive groups of the polymer matrix and form chemical bonds. An effective method of forming such chemical bonds is in situ polymerization where free radicals of the polymer matrix monomer interact with each other and with the carbon nanotubes functional groups simultaneously [155, 156]. These standard functionalization techniques are suitable for reactive polymers. Nonreactive polymers are functionalized through other techniques such as ozone-mediated process [157]. As a result, alkylperoxide and hydroperoxide groups are formed in the polymer chains and decompose into reactive radicals under heat. These radicals target the $\mathrm{sp}^{2}$ hybrid carbons and result in a convenient approach to form chemical bonds between pristine carbon nanotubes and nonreactive polymers. Other techniques such as microwave irradiation $[154,158]$ and plasma enhanced chemical vapor deposition [159] are also reported to be effective.

Nanocomposites with covalent interaction exhibit a better dispersion of the carbon nanotube reinforcements within the polymer matrix [100]. The agglomerated bundles of carbon nanotubes are broken and thus a more uniform behavior can be found [151]. Furthermore, stronger adhesions between the carbon nanotubes and the polymer matrix result in better
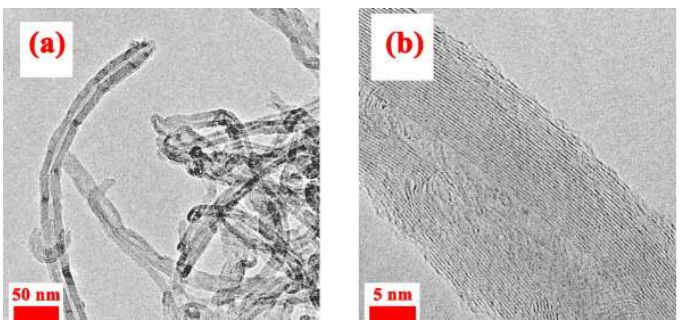

mechanical performance. The effect of functionalization on different characteristics of the nanocomposites has also been evaluated [160]. During the functionalization process, reactive radicals form chemical bonds with the $\mathrm{sp}^{2}$ carbons and convert them into $\mathrm{sp}^{3}$ carbons. Consequently, Raman spectroscopy can distinguish functionalization through increase in the $D$ to $G$ band intensity ratios and in the intensity of $\mathrm{D}$ band which shows the disorders in the carbon nanotubes. Furthermore, the results of thermogravimetric analysis indicated negligible amount of mass loss for pristine multi-walled carbon nanotubes below $1120 \mathrm{~K}$, whereas the mass loss of functionalized carbon nanotubes prior to this temperature is due primarily to the organic polymer chains incorporated to the carbon nanotubes [157]. Scanning electron micrographs of the fractured surface of functionalized nanocomposites showed broken carbon nanotubes and demonstrated a better adhesion between the carbon nanotubes and the polymer matrix [156]. Furthermore, transmission electron micrographs also revealed amorphous polymer layers covering functionalized carbon nanotubes [154, 157], as shown in Figure 8. Finally, the covalent interaction has a stronger influence of carbon nanotube properties on nanocomposite characteristics [161].
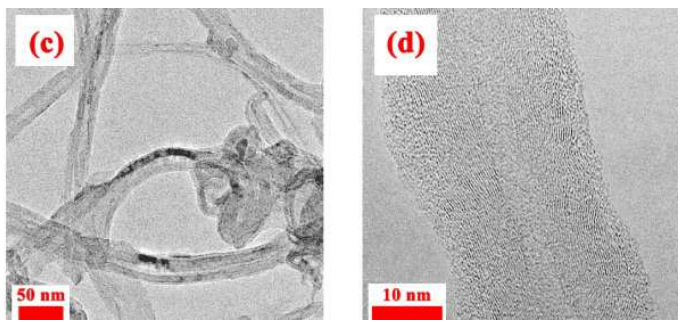

Figure 8. Transmission electron micrographs of $(a, b)$ purified and $(c, d)$ modified multi-walled carbon nanotubes. The polystyrene layer is applied via polymerization of styrene under microwave irradiation to form a middle layer between carbon nanotubes and matrix, resulting in a strong interfacial adhesion. Adapted with permission from Ref. [154].

Functionalization is an effective method that creates covalent interaction and incorporates carbon nanotubes into the polymer network [100]. Consequently, functionalized nanocomposites behave more uniformly and do not show phase separation and poor dispersion. Superior properties are also more likely to be harnessed with functionalization [100]. However, special attention should be paid to purification and other preparation steps during functionalization [156]. Unfortunately, creating covalent bonds between the carbon nanotubes and the polymer matrix requires several preparation steps [100], and needs to be reconsidered in detail. However, the efficiency of the method along with its promising outcomes, especially when hybrid systems of covalent and noncovalent interactions are used [162], compensates for the extra effort.

\section{Property Improvements}

Carbon nanotubes possess extremely high thermal and electrical conductivities, a negative coefficient of thermal expansion, and superior mechanical properties [163-170]. Incorporating carbon nanotubes into polymer matrices affects nanocomposite properties accordingly [171-178]. In particular, the interfacial characteristics directly affect the efficiency of the reinforcements of carbon nanotubes in improving mechanical, thermal, and electrical properties of the polymer nanocomposite [179-187]. The effect of carbon nanotubes is more pronounced when the carbon nanotube-polymer interaction is stronger [188]. It should be noted that the above-mentioned interaction improvement techniques may be employed differently for thermoset [189] and thermoplastic [190] polymers. Thermoset polymers cure irreversibly by forming a three-dimensional network of cross-linked chains. On the other hand, the interaction between the polymer chains in thermoplastics is mostly through van der Waals forces, dipole-dipole interactions or hydrogen bonds [100]. Consequently, thermoplastic polymers may undergo phase transition, e.g., between liquid and solid, by applying or removing heat. Based on the polymer type, i.e., thermoset or thermoplastic, and the selected interaction improvement technique, i.e., covalent or noncovalent, each material system should be considered specifically [100]. For example, when a carbon nanotube is attached to a thermoset polymer through covalent interaction, it becomes part of the three-dimensional network of cross-linked chains. However, for a thermoplastic polymer, a chemically 
functionalized carbon nanotube is covalently attached to given polymer chains that interact with other chains through weaker interactions such as van der Waals forces.

A list of nanocomposite property enhancements has been reported in the literature [100]. The amount of enhancement is a direct measure of the interaction quality. Single-walled and multi-walled carbon nanotubes have been incorporated into a variety of thermoset and thermoplastic polymer matrices [191-196]. The carbon nanotube content is usually very low, due to the effectiveness of carbon nanotubes and nanocomposite manufacturing techniques such as solution mixing. However, extremely high carbon nanotube contents have also been achieved by using different manufacturing techniques and various forms of carbon nanotubes such as buckypaper [135, 197-202]. The improvement percentages cover a very wide range up to almost 40 times improvements [100].

While experimental approaches can result in new material systems or manufacturing techniques, realistic and insightful modelling studies optimize the critical parameters and eliminate the need for impossible or costly experiments [100]. For example, monitoring the Raman spectra of nanocomposites with multi-walled carbon nanotubes revealed that the mechanism of load transfer was different under tension and compression [203]. Furthermore, a friction-like interaction was observed and the load transfer was limited to low strains, above which the carbon nanotube slippage significantly reduced the load transfer [204]. On the other hand, finite element modelling showed that nanocomposites containing carbon nanotubes with aspect ratio of 300 behaved similar to those with continuous carbon nanotubes [205]. Consequently, when the results of modelling and experimental approaches agree, even if the results are not favorable [206, 207], new lessons are learned and further studies are followed.

According to experimental data, there is a variety of successful modelling techniques that predict properties such as Mori-Tanaka [208-210], Halpin-Tsi [211, 212], self-similar [213-215], equivalent-continuum [33, 213], and multi scale models [33, 216]. Each of these modelling strategies has their own advantages, assumptions, and range of validity [100]. A proper modelling approach will result in trustable results if the assumptions and simulation setups are realistic and the input parameters are chosen properly [152]. Since the modelling studies are not limited by the state-of-the-art experimental capabilities, innovative modelling studies may result in new discoveries and guide the experimental and manufacturing efforts toward efficient and optimum material systems [100]. On the other hand, during the modelling approach, the entire picture should be considered in order to avoid results that are limited by indirect restrictions [95, 100, 162]. The other challenge involved in modelling approaches is providing the simulation with proper input parameters $[100,205]$.

On the other hand, experimental data are lower than theoretical predictions such as rule of mixtures [100, 207]. The carbon nanotube-polymer interaction is proposed to be an extremely important factor. The interaction defines the load transfer capacity and directly affects the dispersion of carbon nanotubes in the polymer matrix [217]. Furthermore, the dispersion of carbon nanotubes is significantly affected by the processing parameters during the manufacturing [218]. Consequently, achieving a good dispersion during the preparation phase and before polymerization does not guarantee a strong interaction between the constituents of the final product. Overall, both experimental and modelling studies should consider the effect of processing parameters on the interaction characteristics in order to obtain good interactions in the final nanocomposite [100]. Other influential factors, such as orientation of carbon nanotubes in the polymer matrix [219] and bundle effects, are affected by dispersion [220] and thus by interaction. Consequently, optimizing interaction properties will result in direct and indirect improvements in performance.

\section{Applications of Carbon Nanotube-Polymer Composites}

\subsection{Electrical Conductivity}

Conductive carbon nanotube-polymer composites are regarded as promising materials for use in lithium batteries, supercapacitors, polyactuators, iosensors, and flexible transparent electrodes [12-20]. In particular, new transparent and electrically conductive coatings and films have a variety of fast-growing applications ranging from window glass to flat-panel displays [12-20]. Carbon nanotube-polymer composites do not have high enough electrical conductivity to replace metal wiring [5-8]. However, a number of applications exist where the electrical conductivity requirement is not as severe. Two of those applications are electromagnetic interference shielding [221-224] and electrostatic dissipation $[225,226]$. The difference between them is the electrical conductivity required; the former requires significantly higher electrical conductivities than the latter. Specifically, a particular material is classified as conductive, static conductive, or static dissipative [13]. Materials classified as conductive are useful for electromagnetic interference shielding. Metal cages are used where the shielding requirements are severe. The third application is due to an inherent property of all metals: metals are not optically transparent. Specifically, the requirement is for transparent electrodes [227, 228], for example, the connection between a current source and an active component or between an active component and a current sink [14]. Very thin films of carbon nanotubes with high conductivities can be made and polymers can assist in this process. Flexible electronics, where the carbon nanotubes are deposited on a polymeric substrate, are probably the most common use of carbon nanotubes as transparent electrodes.

\subsection{Thermal Properties}

Significant commercial volume for carbon nanotubes in polymers exists if high thermal conductivities can be achieved $[6,8-20]$. Without a doubt, infused systems offer some promise 
and perhaps in the future carbon nanotubes will be used as layers and coatings designed to dissipate heat. Another application where the high thermal conductivity of carbon nanotubes may play a role in improved performance is flame retardancy [229-234]. Since the mechanism of flame retardancy for carbon nanotubes is as a protective layer [235], it is worth considering this mechanism in more detail. A protective surface layer reduces flammability by reducing the diffusion of oxygen to the surface, reducing the diffusion of gaseous degradation products to the air, and finally acting as a thermal insulating layer reducing the temperature of the polymer underneath [14]. The increase in melt viscosity caused by carbon nanotubes could also contribute to the reduction in flammability [14]. An increase in thermal conductivity could also play an important role if the coating is sufficiently conductive. Carbon nanotubes themselves are flammable at high temperatures; because polymers are less thermally stable than carbon nanotubes, carbon nanotubes are effective flame retardants for polymers. In tests that involve heat release, carbon nanotubes tend to improve the performance of nanocomposites. However, time to ignition has been found to be quicker with carbon nanotube addition, which can be attributed to heat localization due primarily to the high thermal conductivity and low specific heat [232]. Carbon nanotube-filled materials have also been reported to have problems with mass loss on ignition tests [236-238]. Carbon nanotubes have been found to be more effective retardants with respect to heat release at similar loading levels $[239,240]$.

\subsection{Electromechanical Properties}

Carbon nanotubes have the physical property that a change in their mechanical state can induce a change in their ability to conduct electricity, and vice versa [241, 242]. In electromechanical actuation, carbon nanotube-containing materials are connected to a voltage source only at one end. Since no connection exists, current is not able to flow, instead there is a buildup of charge. This buildup of charge can cause a change in the shape of the object, with the change depending on the original object shape, voltage applied, and so on. In strain sensors, a mechanical strain imposed on the carbon nanotubes alters the electronic conductivity, either in an individual sense with respect to individual carbon nanotubes or in a global sense with respect to a carbon nanotube network. Strain sensors work on the principle of measuring a change in electronic properties and converting that change to a strain. A number of theoretical and experimental studies have examined pristine carbon nanotube films as strain sensors $[243,244]$ including carbon nanotubes directly deposited on a polymer substrate $[245,246]$. In fact, freestanding carbon nanotube films do not generally make good strain sensors due to slippage between carbon nanotubes [247].

\section{Conclusion}

Significant progress has been achieved in the area of carbon nanotube-polymer composites over the past two decades. Carbon nanotubes have shown outstanding mechanical, thermal, and electrical properties. However, at the state of the art, their full potential has not been reached when combined with polymer matrices in nanocomposites. In this work, an overview of the research in carbon nanotube-polymer nanocomposites has been provided, with emphases on the principles of carbon nanotube functionalization. Many techniques have been attempted with varying success to functionalize the inherently inert nature of the surface of carbon nanotubes. There are two major approaches, i.e., chemical and physical functionalization. Fluorination, cycloaddition, carbene and nitrene addition, chlorination, bromination, hydrogenation, and silanization belong to the chemical methods that can provide covalent functional groups onto the surface of carbon nanotubes. The physical methods include wrapping of polymer around the carbon nanotubes, use of surfactants of various ionic nature, and the endohedral method. The state of research into carbon nanotube-polymer composites for mechanical reinforcement has been reviewed, and particular interest is also given to interfacial bonding of carbon nanotubes to polymer matrices as it applies to stress transfer from the polymer matrix to the carbon nanotube. The carbon nanotube-polymer interaction is believed to play an important role in determining the overall properties of the nanocomposites. The interfacial characteristics directly affect the efficiency of carbon nanotube reinforcements in improving thermal, electrical, and mechanical properties of the polymer nanocomposite. The interaction studies in carbon nanotube-polymer composites have been critically reviewed. Different techniques of measuring interaction, including experimental and modelling methods, were described, and advantages and challenges of each method were discussed. Furthermore, various techniques of interaction improvement were discussed under the two main classes of covalent and noncovalent interactions. The excellent mechanical properties of carbon nanotubes combined with unique transport properties render a huge potential for structural and functional applications of carbon nanotube-polymer composites. Although numerous studies have dedicated to the development of carbon nanotube-polymer composites for various purposes, their applications in real products are still in their early stage of realization.

Finally, there is large interest in the further development of carbon nanotube-polymer composite materials, which are promising for a broad range of important applications. A very important area in the near future will be the development of new ultra-strong carbon nanotube-polymer materials for application in bullet-proof vests, protective clothing, high performance composites for aircraft, and automotive industries. These large sectors will require huge quantities of carbon nanotubes. For these reasons the development of new cost-effective carbon nanotube-polymer composites will be necessary to meet these needs.

\section{Acknowledgements}

This work was supported by the National Natural Science Foundation of China (No. 51506048). 


\section{References}

[1] S. Iijima. Helical microtubules of graphitic carbon. Nature, Volume 354, Issue 6348, 1991, Pages 56-58.

[2] S. Iijima and T. Ichihashi. Single-shell carbon nanotubes of 1-nm diameter. Nature, Volume 363, Issue 6430, 1993, Pages 603-605.

[3] M. F. L. De Volder, S. H. Tawfick, R. H. Baughman, and A. J. Hart. Carbon nanotubes: present and future commercial applications. Science, Volume 339, Issue 6119, 2013, Pages 535-539.

[4] D. Tasis, N. Tagmatarchis, A. Bianco, and M. Prato. Chemistry of carbon nanotubes. Chemical Reviews, Volume 106, Issue 3, 2006, Pages 1105-1136.

[5] R. Andrews and M. C. Weisenberger. Carbon nanotube polymer composites. Current Opinion in Solid State and Materials Science, Volume 8, Issue 1, 2004, Pages 31-37.

[6] Z. Spitalsky, D. Tasis, K. Papagelis, C. Galiotis. Carbon nanotube-polymer composites: Chemistry, processing, mechanical and electrical properties. Progress in Polymer Science, Volume 35, Issue 3, 2010, Pages 357-401.

[7] S. V. Ahir, Y. Y. Huang, E. M. Terentjev. Polymers with aligned carbon nanotubes: Active composite materials. Polymer, Volume 49, Issue 18, 2008, Pages 3841-3854.

[8] E. T. Thostenson, Z. Ren, and T.-W. Chou. Advances in the science and technology of carbon nanotubes and their composites: a review. Composites Science and Technology, Volume 61, Issue 13, 2001, Pages 1899-1912.

[9] X. Sun, H. Sun, H. Li, and H. Peng. Developing polymer composite materials: Carbon nanotubes or graphene? Advanced Materials, Volume 25, Issue 37, 2013, Pages 5153-5176.

[10] B. L. Wardle, D. S. Saito, E. J. Garcia, A. J. Hart, R. G. de Villoria, and E. A. Verploegen. Fabrication and characterization of ultrahigh-volume-fraction aligned carbon nanotube-polymer composites. Advanced Materials, Volume 20, Issue 14, 2008, Pages 2707-2714.

[11] J. Chen, R. Ramasubramaniam, C. Xue, and H. Liu. A versatile, molecular engineering approach to simultaneously enhanced, multifunctional carbon-nanotube-polymer composites. Advanced Functional Materials, Volume 16, Issue 1, 2006, Pages 114-119.

[12] C Wei, D. Srivastava, and K. Cho. Thermal expansion and diffusion coefficients of carbon nanotube-polymer composites. Nano Letters, Volume 2, Issue 6, 2002, Pages 647-650.

[13] B. P. Grady. Carbon Nanotube-Polymer Composites: Manufacture, Properties, and Applications, Hoboken: John Wiley \& Sons, Inc., 2011.

[14] T. McNally and P. Pötschke. Polymer-Carbon Nanotube Composites: Preparation, Properties and Applications, Cambridge: Woodhead Publishing, 2011.

[15] D. Tasis. Carbon Nanotube-Polymer Composites, London: Royal Society of Chemistry, 2013.

[16] P. M. Ajayan, L. S. Schadler, C. Giannaris, and A. Rubio. Single-walled carbon nanotube-polymer composites: Strength and weakness. Advanced Materials, Volume 12, Issue 10, 2000, Pages 750-753.

[17] Y. Y. Huang and E. M. Terentjev. Tailoring the electrical properties of carbon nanotube-polymer composites. Advanced Functional Materials, Volume 20, Issue 23, 2010, Pages 4062-4068.

[18] D. Fragouli, A. Das, C. Innocenti, Y. Guttikonda, S. Rahman, L. Liu, V. Caramia, C. M. Megaridis, A. Athanassiou. Polymeric films with electric and magnetic anisotropy due to magnetically assembled functional nanofibers. ACS Applied Materials \& Interfaces, Volume 6, Issue 6, 2014, Pages 4535-4541.

[19] M. T. Byrne and Y. K. Gun'ko. Recent advances in research on carbon nanotube-polymer composites. Advanced Materials, Volume 22, Issue 15, 2010, Pages 1672-1688.

[20] L. An, W. Xu, S. Rajagopalan, C. Wang, H. Wang, Y. Fan, L. Zhang, D. Jiang, J. Kapat, L. Chow, B. Guo, J. Liang, and R. Vaidyanathan. Carbon-nanotube-reinforced polymer-derived ceramic composites. Advanced Materials, Volume 16, Issue 22, 2004, Pages 2036-2040.

[21] W. Bauhofer and J. Z. Kovacs. A review and analysis of electrical percolation in carbon nanotube polymer composites. Composites Science and Technology, Volume 69, Issue 10, 2009, Pages 1486-1498.

[22] I. Kang, Y. Y. Heung, J. H. Kim, J. W. Lee, R. Gollapudi, S. Subramaniam, S. Narasimhadevara, D. Hurd, G. R. Kirikera, V. Shanov, M. J. Schulz, D. Shi, J. Boerio, S. Mall, and M. Ruggles-Wren. Introduction to carbon nanotube and nanofiber smart materials. Composites Part B: Engineering, Volume 37, Issue 6, 2006, Pages 382-394.

[23] D. T. Colbert. Single-wall nanotubes: a new option for conductive plastics and engineering polymers. Plastics, Additives and Compounding, Volume 5, Issue 1, 2003, Pages $18-25$.

[24] Y. Shi, G. Zeng, D. Xu, M. Liu, K. Wang, Z. Li, L. Fu, Q. Zhang, X. Zhang, and Y. Wei. Biomimetic PEGylation of carbon nanotubes through surface-initiated RAFT polymerization. Materials Science and Engineering: $C$, Volume 80, 2017, Pages 404-410.

[25] J. K. W. Sandler, J. E. Kirk, I. A. Kinloch, M. S. P. Shaffer, and A. H. Windle. Ultra-low electrical percolation threshold in carbon-nanotube-epoxy composites. Polymer, Volume 44, Issue 19, 2003, Pages 5893-5899.

[26] A. Moisala, Q. Li, I. A. Kinloch, and A. H. Windle. Thermal and electrical conductivity of single- and multi-walled carbon nanotube-epoxy composites. Composites Science and Technology, Volume 66, Issue 10, 2006, Pages 1285-1288.

[27] G. Pal and S. Kumar. Modeling of carbon nanotubes and carbon nanotube-polymer composites. Progress in Aerospace Sciences, Volume 80, 2016, Pages 33-58.

[28] M. J. Biercuk, M. C. Llaguno, M. Radosvljevic, J. K. Hyun, and A. T. Johnson. Carbon nanotube composites for thermal management. Applied Physics Letters, Volume 80, Issue 15, 2002, Pages 2767-2769.

[29] K.-T. Lau, M. Chipara, H.-Y. Ling, and D. Hui. On the effective elastic moduli of carbon nanotubes for nanocomposite structures. Composites Part B: Engineering, Volume 35, Issue 2, 2004, Pages 95-101. 
[30] B. G. Demczyk, Y. M. Wang, J. Cumings, M. Hetman, W. Han, A. Zettl, and R. O. Ritchie. Direct mechanical measurement of the tensile strength and elastic modulus of multiwalled carbon nanotubes. Materials Science and Engineering: A, Volume 334, Issues 1-2, 2002, Pages 173-178.

[31] B. Safadi, R. Andrews, and E. A. Grulke. Multiwalled carbon nanotube polymer composites: Synthesis and characterization of thin films. Journal of Applied Polymer Science, Volume 84, Issue 14, 2002, Pages 2660-2669.

[32] L. Bokobza. Multiwall carbon nanotube elastomeric composites: A review. Polymer, Volume 48, Issue 17, 2007, Pages 4907-4920.

[33] G. M. Odegard, T. S. Gates, K. E. Wise, C. Park, and E. J. Siochi. Constitutive modeling of nanotube-reinforced polymer composites. Composites Science and Technology, Volume 63, Issue 11, 2003, Pages 1671-1687.

[34] G. D. Seidel and D. C. Lagoudas. Micromechanical analysis of the effective elastic properties of carbon nanotube reinforced composites. Mechanics of Materials, Volume 38, Issues 8-10, 2006, Pages 884-907.

[35] J. Zhu, J. Kim, H. Peng, J. L. Margrave, V. N. Khabashesku, and E. V. Barrera. Improving the dispersion and integration of single-walled carbon nanotubes in epoxy composites through functionalization. Nano Letters, Volume 3, Issue 8, 2003, Pages 1107-1113.

[36] P.-C. Ma, N. A. Siddiqui, G. Marom, and J.-K. Kim. Dispersion and functionalization of carbon nanotubes for polymer-based nanocomposites: A review. Composites Part A: Applied Science and Manufacturing, Volume 41, Issue 10, 2010, Pages 1345-1367.

[37] F. Ko, Y. Gogotsi, A. Ali, N. Naguib, H. Ye, G. L. Yang, C. Li, and P. Willis. Electrospinning of continuous carbon nanotube-filled nanofiber yarns. Advanced Materials, Volume 15, Issue 14, 2003, Pages 1161-1165.

[38] J. N. Coleman, U. Khan, and Y. K. Gun'ko. Mechanical reinforcement of polymers using carbon nanotubes. Advanced Materials, Volume 18, Issue 6, 2006, Pages 689-706.

[39] L. Vaisman, H. D. Wagner, and G. Marom. The role of surfactants in dispersion of carbon nanotubes. Advances in Colloid and Interface Science, Volumes 128-130, 2006, Pages 37-46.

[40] A. B. Dalton, S. Collins, E. Muñoz, J. M. Razal, V. H. Ebron, J. P. Ferraris, J. N. Coleman, B. G. Kim, and R. H. Baughman. Super-tough carbon-nanotube fibres. Nature, Volume 423, Issue 6941, 2003, Pages 703-706.

[41] D. S. Bethune, C. H. Kiang, M. S. Devries, G. Gorman, R. Savoy, J. Vazquez, and R. Beyers. Cobalt-catalysed growth of carbon nanotubes with single-atomic-layer walls. Nature, Volume 363, Issue 6430, 1993, Pages 605-607.

[42] V. N. Popov. Carbon nanotubes: properties and application. Materials Science and Engineering: R: Reports, Volume 43, Issue 3, 2004, Pages 61-102.

[43] J.-P. Tessonnier and D. S. Su. Recent progress on the growth mechanism of carbon nanotubes: A review. ChemSusChem, Volume 4, Issue 7, 2011, Pages 824-847.

[44] L. Dai, D. W. Chang, J.-B. Baek, and W. Lu. Carbon nanomaterials for advanced energy conversion and storage.
Small, Volume 8, Issue 8, April 23, 2012, Pages 1130-1166.

[45] R. S. Ruoff and D. C. Lorents. Mechanical and thermal properties of carbon nanotubes. Carbon, Volume 33, Issue 7, 1995, Pages 925-930.

[46] M. S. Dresselhaus, G. Dresselhaus, and R. Saito. Physics of carbon nanotubes. Carbon, Volume 33, Issue 7, 1995, Pages 883-891.

[47] T. Filleter, R. Bernal, S. Li, and H. D. Espinosa. Ultrahigh strength and stiffness in cross-linked hierarchical carbon nanotube bundles. Advanced Materials, Volume 23, Issue 25, 2011, Pages 2855-2860.

[48] H. Dai. Carbon nanotubes: Synthesis, integration, and properties. Accounts of Chemical Research, Volume 35, Issue 12, 2002, Pages 1035-1044.

[49] K. H. An, S. Y. Jeong, H. R. Hwang, and Y. H. Lee. Enhanced sensitivity of a gas sensor incorporating single-walled carbon nanocomposites. Advanced Materials, Volume 16, Issue 12, 2004, Pages 1005-1009.

[50] P. G. Collins, K. Bradley, M. Ishigami, and A. Zettl. Extreme oxygen sensitivity of electronic properties of carbon nanotubes. Science, Volume 287, Issue 5459, 2000, Pages 1801-1804.

[51] T. W. Tombler, C. Zhou, L. Alexseyev, J. Kong, H. Dai, L. Liu, C. S. Jayanthi, M. Tang, and S.-Y. Wu. Reversible electromechanical characteristics of carbon nanotubes under local-probe manipulation. Nature, Volume 405, Issue 6788, 2000, Pages 769-772.

[52] J. N. Coleman, U. Khan, W. J. Blau, and Y. K. Gun'ko. Small but strong: A review of the mechanical properties of carbon nanotube-polymer composites. Carbon, Volume 44, Issue 9, 2006, Pages 1624-1652.

[53] K. Balasubramanian and M. Burghard. Chemically functionalized carbon nanotubes. Small, Volume 1, Issue 2, 2005, Pages 180-192.

[54] R. Saito and M. S. Dresselhaus. Optical properties of carbon nanotubes. In: K. Tanaka and S. Iijima (Eds.), Carbon Nanotubes and Graphene, Amsterdam: Elsevier, Inc., 2014, Pages 77-98.

[55] C. Liu and H.-M. Cheng. Carbon nanotubes: controlled growth and application. Materials Today, Volume 16, Issues 1-2, 2013, Pages 19-28.

[56] A. Hirsch. Functionalization of single-walled carbon nanotubes Angewandte Chemie International Edition, Volume 41, Issue 11, 2002, Pages 1853-1859.

[57] M. Holzinger, O. Vostrowsky, A. Hirsch, F. Hennrich, M. Kappes, R. Weiss, and F. Jellen. Sidewall functionalization of carbon nanotubes. Angewandte Chemie International Edition, Volume 40, Issue 21, 2001, Pages 4002-4005.

[58] A. Eitan, K. Jiang, D. Dukes, R. Andrews, and L. S. Schadler. Surface modification of multiwalled carbon nanotubes: Toward the tailoring of the interface in polymer composites. Chemistry of Materials, Volume 15, Issue 16, 2003, Pages 3198-3201.

[59] E. T. Mickelson, C. B. Huffman, A. G. Rinzler, R. E. Smalley, R. H. Hauge, and J. L. Margrave. Fluorination of single-wall carbon nanotubes. Chemical Physics Letters, Volume 296, Issues 1-2, 1998, Pages 188-194. 
[60] K. F. Kelly, I. W. Chiang, E. T. Mickelson, R. H. Hauge, J. L. Margrave, X. Wang, G. E. Scuseria, C. Radloff, and N. J. Halas. Insight into the mechanism of sidewall functionalization of single-walled nanotubes: an STM study. Chemical Physics Letters, Volume 313, Issues 3-4, 1999, Pages 445-450.

[61] H. Touhara, J. Inahara, T. Mizuno, Y. Yokoyama, S. Okanao, K. Yanagiuch, I. Mukopadhyay, S. Kawasaki, F. Okino, H. Shirai, W. H. Xu, T. Kyotani, and A. Tomita. Property control of new forms of carbon materials by fluorination. Journal of Fluorine Chemistry, Volume 114, Issue 2, 2002, Pages 181-188.

[62] J. L. Stevens, A. Y. Huang, H. Peng, I. W. Chiang, V. N. Khabashesku, and J. L. Margrave. Sidewall amino-functionalization of single-walled carbon nanotubes through fluorination and subsequent reactions with terminal diamines. Nano Letters, Volume 3, Issue 3, 2003, Pages 331-336.

[63] L.-X. Li and F. Li, The effect of carbonyl, carboxyl and hydroxyl groups on the capacitance of carbon nanotubes. New Carbon Materials, Volume 26, Issue 3, 2011, Pages 224-228.

[64] J. Chen, M. A. Hamon, H. Hu, Y. Chen, A. M. Rao, P. C. Eklund, and R. C. Haddon. Solution properties of single-walled carbon nanotubes. Science, Volume 282, Issue 5386, 1998, Pages 95-98.

[65] H. Hu, B. Zhao, M. A. Hamon, K. Kamaras, M. E. Itkis, and R. C. Haddon. Sidewall Functionalization of Single-Walled Carbon Nanotubes by Addition of Dichlorocarbene. Journal of the American Chemical Society, Volume 125, Issue 48, 2003, Pages 14893-14900.

[66] M. Holzinger, J. Abraham, P. Whelan, R. Graupner, L. Ley, F. Hennrich, M. Kappes, and A. Hirsch. Functionalization of single-walled carbon nanotubes with (r-)oxycarbonyl nitrenes. Journal of the American Chemical Society, Volume 125, Issue 28, 2003, Pages 8566-8580.

[67] E. Unger, A. Graham, F. Kreupl, M. Liebau, and W. Hoenlein. Electrochemical functionalization of multi-walled carbon nanotubes for solvation and purification. Current Applied Physics, Volume 2, Issue 2, 2002, Pages 107-111.

[68] K. S. Kim, D. J. Bae, J. R. Kim, K. A. Park, S. C. Lim, J.-J. Kim, W. B. Choi, C. Y. Park, and Y. H. Lee. Modification of electronic structures of a carbon nanotube by hydrogen functionalization. Advanced Materials, Volume 14, Issue 24, 2002, Pages 1818-1821.

[69] C. González-Gaitán, R. Ruiz-Rosas, E. Morallón, and D. Cazorla-Amorós. Functionalization of carbon nanotubes using aminobenzene acids and electrochemical methods. Electroactivity for the oxygen reduction reaction. International Journal of Hydrogen Energy, Volume 40, Issue 34, 2015, Pages $11242-11253$

[70] K. Esumi, M. Ishigami, A. Nakajima, K. Sawada, and H. Honda. Chemical treatment of carbon nanotubes. Carbon, Volume 34, Issue 2, 1996, Pages 279-281.

[71] R. Yu, L. Chen, Q. Liu, J. Lin, K.-L. Tan, S. C. Ng, H. S. O. Chan, G.-Q. Xu, and T. S. A. Hor. Platinum deposition on carbon nanotubes via chemical modification. Chemistry of Materials, Volume 10, Issue 3, 1998, Pages 718-722.

[72] H. Hiura, T. W. Ebbesen, and K. Tanigaki. Opening and purification of carbon nanotubes in high yields. Advanced Materials, Volume 7, Issue 3, 1995, Pages 275-276.

[73] J. Luo, Y. Liu, H. Wei, B. Wang, K.-H. Wu, B. Zhang, and D. S.
Su. A green and economical vapor-assisted ozone treatment process for surface functionalization of carbon nanotubes. Green Chemistry, Volume 19, Issue 4, 2017, Pages 1052-1062.

[74] S. C. Wang, K. S. Chang, and C. J. Yuan. Enhancement of electrochemical properties of screen-printed carbon electrodes by oxygen plasma treatment. Electrochimica Acta, Volume 54, Issue 21, 2009, Pages 4937-4943.

[75] C. A. Ávila-Orta, V. J. Cruz-Delgado, M. G. Neira-Velázquez, E. Hernández-Hernández, M. G. Méndez-Padilla, and F. J. Medellín-Rodríguez. Surface modification of carbon nanotubes with ethylene glycol plasma. Carbon, Volume 47, Issue 8, 2009, Pages 1916-1921.

[76] P. C. Ma, J.-K. Kim, and B. Z. Tang. Functionalization of carbon nanotubes using a silane coupling agent. Carbon, Volume 44, Issue 15, 2006, Pages 3232-3238.

[77] P. Liu. Modifications of carbon nanotubes with polymers. European Polymer Journal, Volume 41, Issue 11, 2005, Pages 2693-2703.

[78] M. A. Hamon, H. Hui, P. Bhowmik, H. M. E. Itkis, and R. C. Haddon. Ester-functionalized soluble single-walled carbon nanotubes. Applied Physics A, Volume 74, Issue 3, 2002, Pages 333-338.

[79] J. Liu, A. G. Rinzler, H. Dai, J. H. Hafner, R. K. Bradley, P. J. Boul, A. Lu, T. Iverson, K. Shelimov, C. B. Huffman, F. Rodriguez-Macias, Y.-S. Shon, T. R. Lee, D. T. Colbert, and R. E. Smalley. Fullerene pipes. Science, Volume 280, Issue 5367, 1998, Pages 1253-1256.

[80] J. J. Stephenson, A. K. Sadana, A. L. Higginbotham, and J. M. Tour. Highly functionalized and soluble multiwalled carbon nanotubes by reductive alkylation and arylation: The Billups reaction. Chemistry of Materials, Volume 18, Issue 19, 2006, Pages 4658-4661.

[81] N. Karousis, N. Tagmatarchis, and D. Tasis. Current progress on the chemical modification of carbon nanotubes. Chemical Reviews, Volume 110, Issue 9, 2010, Pages 5366-5397.

[82] B. Mc Carthy, J. N. Coleman, R. Czerw, A. B. Dalton, D. L. Carroll, and W. J. Blau. Microscopy studies of nanotube-conjugated polymer interactions. Synthetic Metals, Volume 121, Issues 1-3, 2001, Pages 1225-1226.

[83] H. Li, F. Cheng, A. M. Duft, and A. Adronov. Functionalization of single-walled carbon nanotubes with well-defined polystyrene by "click" coupling. Journal of the American Chemical Society, Volume 127, Issue 41, 2005, Pages 14518-14524.

[84] S. Cui, R. Canet, A. Derre, M. Couzi, and P. Delhaes. Characterization of multiwall carbon nanotubes and influence of surfactant in the nanocomposite processing. Carbon, Volume 41, Issue 4, 2003, Pages 797-809.

[85] L. Vaisman, G. Marom, and H. D. Wagner. Dispersions of surface-modified carbon nanotubes in water-soluble and water-insoluble polymers. Advanced Functional Materials, Volume 16, Issue 3, 2006, Pages 357-363.

[86] M. J. O'Connell, S. M. Bachilo, C. B. Huffman, V. C. Moore, M. S. Strano, E. H. Haroz, K. L. Rialon, P. J. Boul, W. H. Noon, C. Kittrell, J. Ma, R. H. Hauge, R. B. Weisman, and R. E. Band gap fluorescence from individual single-walled carbon nanotubes. Science, Volume 297, Issue 5581, 2002, Pages 593-596. 
[87] M. Bystrzejewski, A. Huczko, H. Lange, T. Gemming, B. Büchner, and M. H. Rümmeli. Dispersion and diameter separation of multi-wall carbon nanotubes in aqueous solutions. Journal of Colloid and Interface Science, Volume 345, Issue 2, 2010, Pages 138-142.

[88] T.-H. Kim, C. Doe, S. R. Kline, and S.-M. Choi. Water-redispersible isolated single-walled carbon nanotubes fabricated by in situ polymerization of micelles. Advanced Materials, Volume 19, Issue 7, 2007, Pages 929-933.

[89] E. A. Whitsitt and A. R. Barron. Silica coated single walled carbon nanotubes. Nano Letters, Volume 3, Issue 6, 2003, Pages 775-778.

[90] M. D. Clark, S. Subramanian, and R. Krishnamoorti. Understanding surfactant aided aqueous dispersion of multi-walled carbon nanotubes. Journal of Colloid and Interface Science, Volume 354, Issue 1, 2011, Pages 144-151.

[91] N. Grossiord, J. Loos, O. Regev, and C. E. Koning. Toolbox for dispersing carbon nanotubes into polymers to get conductive nanocomposites. Chemistry of Materials, Volume 18, Issue 5, 2006, Pages 1089-1099.

[92] V. Georgakilas, D. Gournis, V. Tzitzios, L. Pasquato, D. M. Guldi, and M. Prato. Decorating carbon nanotubes with metal or semiconductor nanoparticles. Journal of Materials Chemistry, Volume 17, Issue 26, 2007, Pages 2679-2694.

[93] S. C. Tsang, Z. Guo, Y. K. Chen, M. L. H. Green, H. A. O. Hill, T. W. Hambley, and P. J. Sadler. Immobilization of platinated and iodinated oligonucleotides on carbon nanotubes. Angewandte Chemie International Edition, Volume 36, Issue 20, November 3, 1997, Pages 2198-2200.

[94] W. M. Pachekoski, S. C. Amico, S. H. Pezzin, and J. R. M. d'Almeida. Carbon nanotube hybrid polymer composites: Recent advances in mechanical characterization. In: V. K. Thakur, M. K. Thakur, and A. Pappu (Eds.), Hybrid Polymer Composite Materials: Properties and Characterisation, Duxford: Woodhead Publishing, 2017, Pages 133-150.

[95] M. Wong, M. Paramsothy, X. J. Xu, Y. Ren, S. Li, and K. Liao. Physical interactions at carbon nanotube-polymer interface. Polymer, Volume 44, Issue 25, 2003, Pages 7757-7764.

[96] N. G. Sahoo, S. Rana, J. W. Cho, L. Li, and S. H. Chan. Polymer nanocomposites based on functionalized carbon nanotubes. Progress in Polymer Science, Volume 35, Issue 7, 2010, Pages 837-867.

[97] T. Yamamoto and K. Kawaguchi. Synthesis of composite polymer particles with carbon nanotubes and evaluation of their mechanical properties. Colloids and Surfaces A: Physicochemical and Engineering Aspects, Volume 529, 2017, Pages 765-770.

[98] A. V. Desai and M. A. Haque. Mechanics of the interface for carbon nanotube-polymer composites. Thin-Walled Structures, Volume 43, Issue 11, 2005, Pages 1787-1803.

[99] I. Szleifer and R. Yerushalmi-Rozen. Polymers and carbon nanotubes-dimensionality, interactions and nanotechnology. Polymer, Volume 46, Issue 19, 2005, Pages 7803-7818.

[100] M. Rahmat and P. Hubert. Carbon nanotube-polymer interactions in nanocomposites: A review. Composites Science and Technology, Volume 72, Issue 1, 2011, Pages 72-84.

[101] J. B. Bai. Evidence of the reinforcement role of chemical vapour deposition multi-walled carbon nanotubes in a polymer matrix. Carbon, Volume 41, Issue 6, 2003, Pages 1325-1328.

[102] C.-W. Nan, Z. Shi, and Y. Lin. A simple model for thermal conductivity of carbon nanotube-based composites. Chemical Physics Letters, Volume 375, Issues 5-6, 2003, Pages 666-669.

[103] A. K.-T. Lau, and D. Hui. The revolutionary creation of new advanced materials-carbon nanotube composites. Composites Part B: Engineering, Volume 33, Issue 4, 2002, Pages 263-277.

[104] A. H. Barber, S. R. Cohen, and H. D. Wagner. Measurement of carbon nanotube-polymer interfacial strength. Applied Physics Letters, Volume 82, Issue 23, 2003, Pages 4140-4142.

[105] J.-B. Donnet, T. K. Wang, J. C. M. Peng, and S. Rebouillat. Carbon Fibers, 3rd ed. (revised and expanded edition), New York: Marcel Dekker Inc., 1998.

[106] W. Ding, A. Eitan, F. T. Fisher, X. Chen, D. A. Dikin, R. Andrews, L. C. Brinson, L. S. Schadler, and R. S. Ruoff. Direct observation of polymer sheathing in carbon nanotube-polycarbonate composites. Nano Letters, Volume 3, Issue 11, 2003, Pages 1593-1597.

[107] T. Zhou, X. Wang, X. Liu, and D. Xiong. Influence of multi-walled carbon nanotubes on the cure behavior of epoxy-imidazole system. Carbon, Volume 47, Issue 4, 2009, Pages 1112-1118.

[108] S. J. V. Frankland and V. M. Harik. Analysis of carbon nanotube pull-out from a polymer matrix. Surface Science, Volume 525, Issues 1-3, 2003, Pages L103-L108.

[109] J. Gou, B. Minaie, B. Wang, Z. Liang, and C. Zhang. Computational and experimental study of interfacial bonding of single-walled nanotube reinforced composites. Computational Materials Science, Volume 31, Issues 3-4, 2004, Pages 225-236.

[110] L. Dai and A. W. H. Mau. Surface and interface control of polymeric biomaterials, conjugated polymers, and carbon nanotubes. The Journal of Physical Chemistry B, Volume 104, Issue 9, 2000, Pages 1891-1915.

[111]H. Karami, M. G. Asadi, and M. Mansoori. Pulse electropolymerization and the characterization of polyaniline nanofibers. Electrochimica Acta, Volume 61, 2012, Pages 154-164.

[112] J. H. Burroughes, D. D. C. Bradley, A. R. Brown, R. N. Marks, K. Mackay, R. H. Friend, P. L. Burns, and A. B. Holmes. Light-emitting diodes based on conjugated polymers. Nature, Volume 347, Issue 6293, 1990, Pages 539-541.

[113] J. N. Coleman, A. B. Dalton, S. Curran, A. Rubio, A. P. Davey, A. Drury, B. McCarthy, B. Lahr, P. M. Ajayan, S. Roth, R. C. Barklie, W. J. Blau. Phase separation of carbon nanotubes and turbostratic graphite using a functional organic polymer. Advanced Materials, Volume 12, Issue 3, 2000, Pages 213-216.

[114] H. Zengin, W. Zhou, J. Jin, R. Czerw, D. W. Smith Jr., L. Echegoyen, D. L. Carroll, S. H. Foulger, and J. Ballato. Carbon nanotube doped polyaniline. Advanced Materials, Volume 14, Issue 20, 2002, Pages 1480-1483.

[115] A. B. Dalton, W. J. Blau, G. Chambers, J. N. Coleman, K. Henderson, S. Lefrant, B. McCarthy, C. Stephan, and H. J. Byrne. A functional conjugated polymer to process, purify and selectively interact with single wall carbon nanotubes. Synthetic Metals, Volume 121, Issues 1-3, 2001, Pages 1217-1218. 
[116] A. Star, J. F. Stoddart, D. Steuerman, M. Diehl, A. Boukai, E. W. Wong, X. Yang, S.-W. Chung, H. Choi, and J. R. Heath. Preparation and properties of polymer-wrapped single-walled carbon nanotubes. Angewandte Chemie International Edition, Volume 40, Issue 9, 2001, Pages 1721-1725.

[117] D. W. Steuerman, A. Star, R. Narizzano, H. Choi, R. S. Ries, C. Nicolini, J. F. Stoddart, and J. R. Heath. Interactions between conjugated polymers and single-walled carbon nanotubes. The Journal of Physical Chemistry B, Volume 106, Issue 12, 2002, Pages 3124-3130.

[118] J. H. Rouse. Polymer-assisted dispersion of single-walled carbon nanotubes in alcohols and applicability toward carbon nanotube sol-gel composite formation. Langmuir, Volume 21, Issue 3, 2005, Pages 1055-1061.

[119] J. Wang, J. Dai, and T. Yarlagadda. Carbon nanotube-conducting-polymer composite nanowires. Langmuir, Volume 21, Issue 1, 2005, Pages 9-12.

[120]Z. Guo, P. J. Sadler, and S. C. Tsang. Immobilization and visualization of DNA and proteins on carbon nanotubes. Advanced Materials, Volume 10, Issue 9, 1998, Pages 701-703.

[121] S. G. Chou, H. B. Ribeiro, E. B. Barros, A. P. Santos, D. Nezich, Ge. G. Samsonidze, C. Fantini, M. A. Pimenta, A. Jorio, F. Plentz Filho, M. S. Dresselhaus, G. Dresselhaus, R. Saito, M. Zheng, G. B. Onoa, E. D. Semke, A. K. Swan, M. S. Ünlü, and B. B. Goldberg. Optical characterization of DNA-wrapped carbon nanotube hybrids. Chemical Physics Letters, Volume 397, Issues 4-6, 2004, Pages 296-301.

[122] M. Zheng, A. Jagota, E. D. Semke, B. A. Diner, R. S. Mclean, S R. Lustig, R. E. Richardson, and N. G. Tassi. DNA-assisted dispersion and separation of carbon nanotubes. Nature Materials, Volume 2, Issue 5, 2003, Pages 338-342.

[123] M. Zheng, A. Jagota, M. S. Strano, A. P. Santos, P. Barone, S. G. Chou, B. A. Diner, M. S. Dresselhaus, R. S. Mclean, G. B. Onoa, G. G. Samsonidze, E. D. Semke, M. Usrey, and D. J. Walls. Structure-based carbon nanotube sorting by sequence-dependent DNA assembly. Science, Volume 302, Issue 5650, 2003, Pages 1545-1548.

[124] O. P. Matyshevska, A. Yu. Karlash, Y. V. Shtogun, A. Benilov, Yu. Kirgizov, K. O. Gorchinskyy, E. V. Buzaneva, Y. I. Prylutskyy, and P. Scharff. Self-organizing DNA-carbon nanotube molecular films. Materials Science and Engineering: $C$, Volume 15, Issues 1-2, 2001, Pages 249-252.

[125] B. F. Erlanger, B.-X. Chen, M. Zhu, and L. Brus. Binding of an anti-fullerene $\operatorname{IgG}$ monoclonal antibody to single wall carbon nanotubes. Nano Letters, Volume 1, Issue 9, 2001, Pages 465-467.

[126] J. N. Barisci, M. Tahhan, G. G. Wallace, S. Badaire, T. Vaugien, M. Maugey, and P. Poulin. Properties of carbon nanotube fibers spun from DNA-stabilized dispersions. Advanced Functional Materials, Volume 14, Issue 2, 2004, Pages 133-138.

[127] K. Keren, S. R. Berman, E. Buchstab, U. Sivan, and E. Braun. DNA-templated carbon nanotube field-effect transistor. Science, Volume 302, Issue 5649, 2003, Pages 1380-1382.

[128] H. Gao and Y. Kong. Simulation of DNA-nanotube interactions. Annual Review of Materials Research, Volume 34, 2004, Pages 123-150.

[129] G. R. Dieckmann, A. B. Dalton, P. A. Johnson, J. Razal, J.
Chen, G. M. Giordano, E. Muñoz, I. H. Musselman, R. H. Baughman, and R. K. Draper. Controlled assembly of carbon nanotubes by designed amphiphilic peptide helices. Journal of the American Chemical Society, Volume 125, Issue 7, 2003, Pages 1770-1777.

[130] M. J. O'Connell, P. Boul, L. M. Ericson, C. Huffman, Y. Wang, E. Haroz, C. Kuper, J. Tour, K. D. Ausman, and R. E. Smalley. Reversible water-solubilization of single-walled carbon nanotubes by polymer wrapping. Chemical Physics Letters, Volume 342, Issues 3-4, 2001, Pages 265-271.

[131] A. Star, D. W. Steuerman, J. R. Heath, and J. F. Stoddart. Starched carbon nanotubes. Angewandte Chemie International Edition, Volume 41, Issue 14, 2002, Pages 2508-2512.

[132] H. D. Wagner and R. A. Vaia. Nanocomposites: issues at the interface. Materials Today, Volume 7, Issue 11, 2004, Pages $38-42$.

[133] S. Gotovac, H. Honda, Y. Hattori, K. Takahashi, H. Kanoh, and K. Kaneko. Effect of nanoscale curvature of single-walled carbon nanotubes on adsorption of polycyclic aromatic hydrocarbons. Nano Letters, Volume 7, Issue 3, 2007, Pages 583-587.

[134] J. Moreno, S. Aspera, M. David, and H. Kasai. A computational study on the effect of local curvature on the adsorption of oxygen on single-walled carbon nanotubes. Carbon, Volume 94, 2015, Pages 936-941.

[135] M. M. Zaeri, S. Ziaei-Rad, A. Vahedi, and F. Karimzadeh. Mechanical modelling of carbon nanomaterials from nanotubes to buckypaper. Carbon, Volume 48, Issue 13, 2010, Pages 3916-3930.

[136] M.-F. Yu, B. I. Yakobson, and R. S. Ruoff. Controlled sliding and pullout of nested shells in individual multiwalled carbon nanotubes. The Journal of Physical Chemistry B, Volume 104, Issue 37, 2000, Pages 8764-8767.

[137] D. Qian, W. K. Liu, and R. S. Ruoff. Load transfer mechanism in carbon nanotube ropes. Composites Science and Technology, Volume 63, Issue 11, 2003, Pages 1561-1569.

[138] D. Qian, E. C. Dickey, R. Andrews, and T. Rantell. Load transfer and deformation mechanisms in carbon nanotube-polystyrene composites. Applied Physics Letters, Volume 76, Issue 20, 2000, Pages 2868-2870.

[139] L.-G. Tang and J. L. Kardos. A review of methods for improving the interfacial adhesion between carbon fiber and polymer matrix. Polymer Composites, Volume 18, Issue 1, 1997, Pages 100-113.

[140] M. Mu and K. I. Winey. Improved load transfer in nanotube-polymer composites with increased polymer molecular weight. The Journal of Physical Chemistry C, Volume 111, Issue 48, 2007, Pages 17923-17927.

[141] M. Cadek, J. N. Coleman, K. P. Ryan, V. Nicolosi, G. Bister, A. Fonseca, J. B. Nagy, K. Szostak, F. Béguin, and W. J. Blau. Reinforcement of polymers with carbon nanotubes: The role of nanotube surface area. Nano Letters, Volume 4, Issue 2, 2004, Pages 353-356.

[142] J. Gao, M. A. Loi, E. J. F. de Carvalho, and M. C. dos Santos. Selective wrapping and supramolecular structures of polyfluorene-carbon nanotube hybrids. ACS Nano, Volume 5, Issue 5, 2011, Pages 3993-3999. 
[143] W. Yi, A. Malkovskiy, Y. Xu, X.-Q. Wang, A. P. Sokolov, M. Lebron-Colon, M. A. Meador, and Y. Pang. Polymer conformation-assisted wrapping of single-walled carbon nanotube: The impact of cis-vinylene linkage. Polymer, Volume 51, Issue 2, 2010, Pages 475-481.

[144] S. S. Tallury and M. A. Pasquinelli. Molecular dynamics simulations of polymers with stiff backbones interacting with single-walled carbon nanotubes. The Journal of Physical Chemistry B, Volume 114, Issue 29, 2010, Pages 9349-9355.

[145] I. Kusner and S. Srebnik. Conformational behavior of semi-flexible polymers confined to a cylindrical surface. Chemical Physics Letters, Volume 430, Issues 1-3, 2006, Pages 84-88

[146] S. S. Tallury and M. A. Pasquinelli. Molecular dynamics simulations of flexible polymer chains wrapping single-walled carbon nanotubes. The Journal of Physical Chemistry B, Volume 114, Issue 12, 2010, Pages 4122-4129.

[147] H. Wang, J. Mei, P. Liu, K. Schmidt, G. Jiménez-Osés, S. Osuna, L. Fang, C. J. Tassone, A. P. Zoombelt, A. N. Sokolov, K. N. Houk, M. F. Toney, and Z. Bao. Scalable and selective dispersion of semiconducting arc-discharged carbon nanotubes by dithiafulvalene-thiophene copolymers for thin film transistors. ACS Nano, Volume 7, Issue 3, 2013, Pages 2659-2668.

[148] S. Zhang, W. Lin, C.-P. Wong, D. G. Bucknall, and S. Kumar. Nanocomposites of carbon nanotube fibers prepared by polymer crystallization. ACS Applied Materials \& Interfaces, Volume 2, Issue 6, 2010, Pages 1642-1647.

[149] V. V. Didenko, V. C. Moore, D. S. Baskin, and R. E. Smalley. Visualization of individual single-walled carbon nanotubes by fluorescent polymer wrapping. Nano Letters, Volume 5, Issue 8, 2005, Pages 1563-1567.

[150] W. S. Choi, and S. H. Ryu. Improvement of interfacial interaction via ATRP in polycarbonate-carbon nanotube nanocomposites. Colloids and Surfaces A: Physicochemical and Engineering Aspects, Volume 375, Issues 1-3, 2011, Pages $55-60$

[151] F. Buffa, G. A. Abraham, B. P. Grady, and D. Resasco. Effect of nanotube functionalization on the properties of single-walled carbon nanotube-polyurethane composites. Journal of Polymer Science Part B: Polymer Physics, Volume 45, Issue 4, 2007, Pages 490-501.

[152] Q. Zheng, Q. Xue, K. Yan, X. Gao, Q. Li, and L. Hao. Effect of chemisorption on the interfacial bonding characteristics of carbon nanotube-polymer composites. Polymer, Volume 49, Issue 3, 2008, Pages 800-808.

[153] T. Ramanathan, A. A. Abdala, S. Stankovich, D. A. Dikin, M. Herrera-Alonso, R. D. Piner, D. H. Adamson, H. C. Schniepp, X. Chen, R. S. Ruoff. Functionalized graphene sheets for polymer nanocomposites. Nature Nanotechnology, Volume 3, Issue 6, 2008, Pages 327-331.

[154] J.-M. Yuan, Z.-F. Fan, X.-H. Chen, X.-H. Chen, Z.-J. Wu, and L.-P. He. Preparation of polystyrene-multiwalled carbon nanotube composites with individual-dispersed nanotubes and strong interfacial adhesion. Polymer, Volume 50, Issue 14, 2009, Pages 3285-3291.

[155] C. Velasco-Santos, A. L. Martínez-Hernández, F. T. Fisher, R. Ruoff, and V. M. Castaño. Improvement of thermal and mechanical properties of carbon nanotube composites through chemical functionalization. Chemistry of Materials, Volume 15 , Issue 23, 2003, Pages 4470-4475.

[156] N. G. Sahoo, H. K. F. Cheng, J. Cai, L. Li, S. H. Chan, J. Zhao, and S. Yu. Improvement of mechanical and thermal properties of carbon nanotube composites through nanotube functionalization and processing methods. Materials Chemistry and Physics, Volume 117, Issue 1, 2009, Pages 313-320.

[157] C.-M. Chang and Y.-L. Liu. Functionalization of multi-walled carbon nanotubes with non-reactive polymers through an ozone-mediated process for the preparation of a wide range of high performance polymer-carbon nanotube composites. Carbon, Volume 48, Issue 4, 2010, Pages 1289-1297.

[158] S. Mallakpour and A. Zadehnazari. A facile, efficient, and rapid covalent functionalization of multi-walled carbon nanotubes with natural amino acids under microwave irradiation. Progress in Organic Coatings, Volume 77, Issue 3, 2014, Pages 679-684.

[159] R. E. Gorga, K. K. S. Lau, K. K. Gleason, and R. E. Cohen. The importance of interfacial design at the carbon nanotube-polymer composite interface. Journal of Applied Polymer Science, Volume 102, Issue 2, 2006, Pages 1413-1418.

[160] N. Lachman and H. D. Wagner. Correlation between interfacial molecular structure and mechanics in CNT-epoxy nano-composites. Composites Part A: Applied Science and Manufacturing, Volume 41, Issue 9, 2010, Pages 1093-1098.

[161] S. Wang, Z. Liang, P. Gonnet, Y.-H. Liao, B. Wang, and C. Zhang. Effect of nanotube functionalization on the coefficient of thermal expansion of nanocomposites. Advanced Functional Materials, Volume 17, Issue 1, 2007, Pages 87-92.

[162] J. Q. Liu, T. Xiao, K. Liao, and P. Wu. Interfacial design of carbon nanotube polymer composites: a hybrid system of noncovalent and covalent functionalizations. Nanotechnology, Volume 18, Issue 16, 2007, Pages 165701-165706.

[163] J. Hone, M. Whitney, and A. Zettl. Thermal conductivity of single-walled carbon nanotubes. Synthetic Metals, Volume 103, Issues 1-3, 1999, Pages 2498-2499.

[164]R. N. Salaway and L. V. Zhigilei. Molecular dynamics simulations of thermal conductivity of carbon nanotubes: Resolving the effects of computational parameters. International Journal of Heat and Mass Transfer, Volume 70, 2014, Pages 954-964.

[165] K. Chu, Q. Wu, C. Jia, X. Liang, J. Nie, W. Tian, G. Gai, and H. Guo. Fabrication and effective thermal conductivity of multi-walled carbon nanotubes reinforced $\mathrm{Cu}$ matrix composites for heat sink applications. Composites Science and Technology, Volume 70, Issue 2, 2010, Pages 298-304.

[166] S. Zhao, Z. Zheng, Z. Huang, S. Dong, P. Luo, Z. Zhang, and Y. Wang. $\mathrm{Cu}$ matrix composites reinforced with aligned carbon nanotubes: Mechanical, electrical and thermal properties. Materials Science and Engineering: A, Volume 675, 2016, Pages 82-91.

[167] Y.-P. Sun, K. Fu, Y. Lin, and W. Huang. Functionalized carbon nanotubes: Properties and applications. Accounts of Chemical Research, Volume 35, Issue 12, 2002, Pages 1096-1104.

[168] J.-P. Issi, L. Langer, J. Heremans, and C. H. Olk. Electronic properties of carbon nanotubes: Experimental results. Carbon, Volume 33, Issue 7, 1995, Pages 941-948. 
[169] J. W. Mintmire and C. T. White. Electronic and structural properties of carbon nanotubes. Carbon, Volume 33, Issue 7, 1995, Pages 893-902.

[170] L.-M. Peng, Z. Zhang, and S. Wang. Carbon nanotube electronics: recent advances. Materials Today, Volume 17, Issue 9, 2014, Pages 433-442.

[171] T. V. Sreekumar, T. Liu, B. G. Min, H. Guo, S. Kumar, R. H. Hauge, and R. E. Smalley. Polyacrylonitrile single-walled carbon nanotube composite fibers. Advanced Materials, Volume 16, Issue 1, 2004, Pages 58-61.

[172]E. Karpushkin, N. Gvozdik, M. Klimenko, S. K. Filippov, B. Angelov, I. Bessonov, and V. Sergeyev. Structure and flow behavior of dilute dispersions of carbon nanotubes in polyacrylonitrile-dimethylsulfoxide solution. Colloid and Polymer Science, Volume 294, Issue 7, 2016, Pages 1187-1195.

[173] H. G. Chae, T. V. Sreekumar, T. Uchida, and S. Kumar. A comparison of reinforcement efficiency of various types of carbon nanotubes in polyacrylonitrile fiber. Polymer, Volume 46, Issue 24, 2005, Pages 10925-10935.

[174] Z. Han and A. Fina. Thermal conductivity of carbon nanotubes and their polymer nanocomposites: A review. Progress in Polymer Science, Volume 36, Issue 7, 2011, Pages 914-944.

[175] H. S. Kim, J.-U. Jang, J. Yu, and S. Y. Kim. Thermal conductivity of polymer composites based on the length of multi-walled carbon nanotubes. Composites Part B: Engineering, Volume 79, 2015, Pages 505-512.

[176]F. Gong, K. Bui, D. V. Papavassiliou, and H. M. Duong. Thermal transport phenomena and limitations in heterogeneous polymer composites containing carbon nanotubes and inorganic nanoparticles. Carbon, Volume 78, 2014, Pages 305-316.

[177] J. Bouchard, A. Cayla, E. Devaux, and C. Campagne. Electrical and thermal conductivities of multiwalled carbon nanotubes-reinforced high performance polymer nanocomposites. Composites Science and Technology, Volume 86, 2013, Pages 177-184.

[178] W. Fang, H. W. Jang, and S. N. Leung. Evaluation and modelling of electrically conductive polymer nanocomposites with carbon nanotube networks. Composites Part B: Engineering, Volume 83, 2015, Pages 184-193.

[179] H. S. Kim, J. H. Kim, C.-M. Yang, and S. Y. Kim. Synergistic enhancement of thermal conductivity in composites filled with expanded graphite and multi-walled carbon nanotube fillers via melt-compounding based on polymerizable low-viscosity oligomer matrix. Journal of Alloys and Compounds, Volume 690, 2017, Pages 274-280.

[180] J. Huang, M. Gao, T. Pan, Y. Zhang, and Y. Lin. Effective thermal conductivity of epoxy matrix filled with poly(ethyleneimine) functionalized carbon nanotubes. Composites Science and Technology, Volume 95, 2014, Pages 16-20.

[181] P. S. Goh, A. F. Ismail, and B. C. Ng. Directional alignment of carbon nanotubes in polymer matrices: Contemporary approaches and future advances. Composites Part A: Applied Science and Manufacturing, Volume 56, 2014, Pages 103-126.

[182] K. Wu, Y. Li, R. Huang, S. Chai, F. Chen, and Q. Fu. Constructing conductive multi-walled carbon nanotubes network inside hexagonal boron nitride network in polymer composites for significantly improved dielectric property and thermal conductivity. Composites Science and Technology, Volume 151, 2017, Pages 193-201.

[183] F. Nilsson, J. Krückel, D. W. Schubert, F. Chen, M. Unge, U. W. Gedde, and M. S. Hedenqvist. Simulating the effective electric conductivity of polymer composites with high aspect ratio fillers. Composites Science and Technology, Volume 132, 2016, Pages 16-23.

[184] T. Ji, Y. Feng, M. Qin, and W. Feng. Thermal conducting properties of aligned carbon nanotubes and their polymer composites. Composites Part A: Applied Science and Manufacturing, Volume 91, Part 1, 2016, Pages 351-369.

[185] V. D. Punetha, S. Rana, H. J. Yoo, A. Chaurasia, J. T. McLeskey, M. S. Ramasamy, N. G. Sahoo, and J. W. Cho. Functionalization of carbon nanomaterials for advanced polymer nanocomposites: A comparison study between CNT and graphene. Progress in Polymer Science, Volume 67, 2017, Pages 1-47.

[186] M. Safdari and M. S. Al-Haik. Synergistic electrical and thermal transport properties of hybrid polymeric nanocomposites based on carbon nanotubes and graphite nanoplatelets. Carbon, Volume 64, 2013, Pages 111-121.

[187] G. Mittal, V. Dhand, K. Y. Rhee, S.-J. Park, and W. R. Lee. A review on carbon nanotubes and graphene as fillers in reinforced polymer nanocomposites. Journal of Industrial and Engineering Chemistry, Volume 21, 2015, Pages 11-25.

[188] C. Bartholome, P. Miaudet, A. Derré, M. Maugey, O. Roubeau, C. Zakri, and P. Poulin. Influence of surface functionalization on the thermal and electrical properties of nanotube-PVA composites. Composites Science and Technology, Volume 68, Issue 12, 2008, Pages 2568-2573.

[189] L. Guadagno, B. De Vivo, A. Di Bartolomeo, P. Lamberti, A. Sorrentino, V. Tucci, L. Vertuccio, and V. Vittoria. Effect of functionalization on the thermo-mechanical and electrical behavior of multi-wall carbon nanotube-epoxy composites. Carbon, Volume 49, Issue 6, 2011, Pages 1919-1930.

[190] K. T. Kim and W. H. Jo. Non-destructive functionalization of multi-walled carbon nanotubes with naphthalene-containing polymer for high performance Nylon 66-multi-walled carbon nanotube composites. Carbon, Volume 49, Issue 3, 2011, Pages 819-826.

[191] G. Pal and S. Kumar. Modeling of carbon nanotubes and carbon nanotube-polymer composites. Progress in Aerospace Sciences, Volume 80, 2016, Pages 33-58.

[192] A. El Moumen, M. Tarfaoui, and K. Lafdi. Mechanical characterization of carbon nanotubes based polymer composites using indentation tests. Composites Part B: Engineering, Volume 114, 2017, Pages 1-7.

[193]N. Terasawa and K. Asaka. Electrochemical and Electromechanical Properties of Activated Multi-walled Carbon Nanotube Polymer Actuator that Surpass the Performance of a Single-walled Carbon Nanotube Polymer Actuator. Materials Today: Proceedings, Volume 3, Supplement 2, 2016, Pages S178-S183.

[194] M. Castellino, M. Rovere, M. I. Shahzad, and A. Tagliaferro. Conductivity in carbon nanotube polymer composites: A comparison between model and experiment. Composites Part A: Applied Science and Manufacturing, Volume 87, 2016, Pages 237-242. 
[195] J. B. In, H.-J. Kwon, J.-H. Yoo, F. I. Allen, A. M. Minor, and C. P. Grigoropoulos. Laser welding of vertically aligned carbon nanotube arrays on polymer workpieces. Carbon, Volume 115, 2017, Pages 688-693.

[196] E. M. Jackson, P. E. Laibinis, W. E. Collins, A. Ueda, C. D. Wingard, and B. Penn. Development and thermal properties of carbon nanotube-polymer composites. Composites Part B: Engineering, Volume 89, 2016, Pages 362-373.

[197] Y. Cai, L. Chen, H. Yang, J. Gou, L. Cheng, X. Yin, and H. Yin. Mechanical and electrical properties of carbon nanotube buckypaper reinforced silicon carbide nanocomposites. Ceramics International, Volume 42, Issue 4, 2016, Pages 4984-4992.

[198] J. M. Sieben, A. Ansón-Casaos, F. Montilla, M. T. Martínez, and E. Morallón. Electrochemical behaviour of different redox probes on single wall carbon nanotube buckypaper-modified electrodes. Electrochimica Acta, Volume 135, 2014, Pages 404-411.

[199] Md. H.-O. Rashid, S. Q. T. Pham, L. J. Sweetman, L. J. Alcock, A. Wise, L. D. Nghiem, G. Triani. Marc in het Panhuis, Stephen F. Ralph, Synthesis, properties, water and solute permeability of MWNT buckypapers. Journal of Membrane Science, Volume 456, 2014, Pages 175-184.

[200] Md. H.-O. Rashid, G. Triani, N. Scales, M. in het Panhuis, L. D. Nghiem, and S. F. Ralph. Nanofiltration applications of tough MWNT buckypaper membranes containing biopolymers. Journal of Membrane Science, Volume 529, 2017, Pages 23-34.

[201] H. Chen, L. Zhang, J. Chen, M. Becton, X. Wang, and H. Nie. Energy dissipation capability and impact response of carbon nanotube buckypaper: A coarse-grained molecular dynamics study. Carbon, Volume 103, 2016, Pages 242-254.

[202] M. F. Arif, S. Kumar, and T. Shah. Tunable morphology and its influence on electrical, thermal and mechanical properties of carbon nanostructure-buckypaper. Materials \& Design, Volume 101, 2016, Pages 236-244.

[203] L. S. Schadler, S. C. Giannaris, and P. M. Ajayan. Load transfer in carbon nanotube epoxy composites. Applied Physics Letters, Volume 73, Issue 26, 1998, Pages 3842-3844.

[204] M. Mu, S. Osswald, Y. Gogotsi, and K. I. Winey. An in situ Raman spectroscopy study of stress transfer between carbon nanotubes and polymer. Nanotechnology, Volume 20, Issue 33, 2009, Pages 1-7.

[205] H. R. Lusti and A. A. Gusev. Finite element predictions for the thermoelastic properties of nanotube reinforced polymers. Modelling and Simulation in Materials Science and Engineering, Volume 12, Issue 3, 2004, Pages S107-S119.

[206] A. S. dos Santos, T. de O. N. Leite, C. A. Furtado, C. Welter, L. C. Pardini, and G. G. Silva. Morphology, thermal expansion, and electrical conductivity of multiwalled carbon nanotube-epoxy composites. Journal of Applied Polymer Science, Volume 108, Issue 2, 2008, Pages 979-986.

[207] S. J. V. Frankland, V. M. Harik, G. M. Odegard, D. W. Brenner, and T. S. Gates. The stress-strain behavior of polymer-nanotube composites from molecular dynamics simulation. Composites Science and Technology, Volume 63, Issue 11, 2003, Pages 1655-1661.

[208] T. Mori and K. Tanaka. Average stress in matrix and average elastic energy of materials with misfitting inclusions. Acta
Metallurgica, Volume 21, Issue 5, 1973, Pages 571-574.

[209] G. M. Odegard and T. S. Gates. Modeling and testing of the viscoelastic properties of a graphite nanoplatelet-epoxy composite. Journal of Intelligent Material Systems and Structures, Volume 17, Issue 3, 2006, Pages 239-246.

[210] K. M. Liew, Z. X. Lei, J. L. Yu, and L. W. Zhang. Postbuckling of carbon nanotube-reinforced functionally graded cylindrical panels under axial compression using a meshless approach. Computer Methods in Applied Mechanics and Engineering, Volume 268, 2014, Pages 1-17.

[211] J. C. Halpin. Stiffness and expansion estimates for oriented short fiber composites. Journal of Composite Materials, Volume 3, Issue 4, 1969, Pages 732-734.

[212] C. L. Tucker III and E. Liang. Stiffness predictions for unidirectional short-fiber composites: Review and evaluation. Composites Science and Technology, Volume 59, Issue 5, 1999, Pages 655-671.

[213] G. M. Odegard, R. B. Pipes, and P. Hubert. Comparison of two models of SWCN polymer composites. Composites Science and Technology, Volume 64, Issues 7-8, 2004, Pages 1011-1020.

[214] R. B. Pipes, S. J. V. Frankland, P. Hubert, and E. Saether. Self-consistent properties of carbon nanotubes and hexagonal arrays as composite reinforcements. Composites Science and Technology, Volume 63, Issue 10, 2003, Pages 1349-1358.

[215]R. B. Pipes and P. Hubert. Scale effects in carbon nanostrutures: Self-similar analysis. Nano Letters, Volume 3, Issue 2, 2003, Pages 239-243.

[216] T. S. Gates, G. M. Odegard, S. J. V. Frankland, and T. C. Clancy. Computational materials: Multi-scale modeling and simulation of nanostructured materials. Composites Science and Technology, Volume 65, Issues 15-16, 2005, Pages 2416-2434.

[217] X.-M. Sui, S. Giordani, M. Prato, and H. D. Wagner. Effect of carbon nanotube surface modification on dispersion and structural properties of electrospun fibers. Applied Physics Letters, Volume 95, Issue 23, 2009, Pages 1-3.

[218] V. Mirjalili, R. Ramachandramoorthy, and P. Hubert. Enhancement of fracture toughness of carbon fiber laminated composites using multi wall carbon nanotubes. Carbon, Volume 79, 2014, Pages 413-423.

[219] Z. Fan and S. G. Advani. Characterization of orientation state of carbon nanotubes in shear flow. Polymer, Volume 46, Issue 14, 2005, Pages 5232-5240.

[220] F. H. Gojny, M. H. G. Wichmann, U. Köpke, B. Fiedler, and K. Schulte. Carbon nanotube-reinforced epoxy-composites: enhanced stiffness and fracture toughness at low nanotube content. Composites Science and Technology, Volume 64, Issue 15, 2004, Pages 2363-2371.

[221] M. H. Al-Saleh and U. Sundararaj. Electromagnetic interference shielding mechanisms of CNT-polymer composites. Carbon, Volume 47, Issue 7, 2009, Pages 1738-1746.

[222] C.-S. Zhang, Q.-Q. Ni, S.-Y. Fu, and K. Kurashiki. Electromagnetic interference shielding effect of nanocomposites with carbon nanotube and shape memory polymer. Composites Science and Technology, Volume 67, Issue 14, 2007, Pages 2973-2980. 
[223] S. Kwon, R. Ma, U. Kim, H. R. Choi, and S. Baik, Flexible electromagnetic interference shields made of silver flakes, carbon nanotubes and nitrile butadiene rubber. Carbon, Volume 68, 2014, Pages 118-124.

[224] K. Hayashida and Y. Matsuoka. Electromagnetic interference shielding properties of polymer-grafted carbon nanotube composites with high electrical resistance. Carbon, Volume 85, 2015, Pages 363-371.

[225] L. Valentini, S. B. Bon, and J. M. Kenny. Electrodeposited carbon nanotubes as template for the preparation of semi-transparent conductive thin films by in situ polymerization of methyl methacrylate. Carbon, Volume 45, Issue 13, 2007, Pages 2685-2691.

[226] P. V. Kamat, K. G. Thomas, S. Barazzouk, G. Girishkumar, K. Vinodgopal, and D. Meisel. Self-assembled linear bundles of single wall carbon nanotubes and their alignment and deposition as a film in a dc field. Journal of the American Chemical Society, Volume 126, Issue 34, 2004, Pages 10757-10762.

[227] S. L. Hellstrom, H. W. Lee, and Z. Bao. Polymer-assisted direct deposition of uniform carbon nanotube bundle networks for high performance transparent electrodes. ACS Nano, Volume 3, Issue 6, 2009, Pages 1423-1430.

[228] J. Ben-David, A. J. Stapleton, C. T. Gibson, A. Sharma, A. R. Gentle, D. A. Lewis, and A. V. Ellis. Poly (3,4-ethylenedioxythiophene): polystyrene sulfonate-free silver nanowire-single walled carbon nanotube transparent electrodes using graphene oxide. Thin Solid Films, Volume 616, 2016, Pages 515-520.

[229] A. B. Morgan and C. A. Wilkie. Flame Retardant Polymer Nanocomposites, Hoboken: John Wiley \& Sons, Inc., 2007.

[230] S. Ullah, F. Ahmad, A. M. Shariff, M. R. Raza, and P. J. Masset. The role of multi-wall carbon nanotubes in char strength of epoxy based intumescent fire retardant coating. Journal of Analytical and Applied Pyrolysis, Volume 124, 2017, Pages 149-160.

[231] S. Wang, F. Xin, Y. Chen, L. Qian, and Y. Chen. Phosphorus-nitrogen containing polymer wrapped carbon nanotubes and their flame-retardant effect on epoxy resin. Polymer Degradation and Stability, Volume 129, 2016, Pages 133-141.

[232] G. Huang, S. Wang, P. Song, C. Wu, S. Chen, and X. Wang. Combination effect of carbon nanotubes with graphene on intumescent flame-retardant polypropylene nanocomposites. Composites Part A: Applied Science and Manufacturing, Volume 59, 2014, Pages 18-25.

[233] N. A. Isitman and C. Kaynak. Nanoclay and carbon nanotubes as potential synergists of an organophosphorus flame-retardant in poly(methyl methacrylate). Polymer Degradation and Stability, Volume 95, Issue 9, 2010, Pages 1523-1532.

[234] T. Orhan, N. A. Isitman, J. Hacaloglu, and C. Kaynak. Thermal degradation of organophosphorus flame-retardant poly(methyl methacrylate) nanocomposites containing nanoclay and carbon nanotubes. Polymer Degradation and Stability, Volume 97, Issue 3, 2012, Pages 273-280.

[235] T. Kashiwagi, E. Grulke, J. Hilding, K. Groth, R. Harris, K. Butler, J. Shields, S. Kharchenko, and J. Douglas. Thermal and flammability properties of polypropylene-carbon nanotube nanocomposites. Polymer, Volume 45, Issue 12, 2004, Pages 4227-4239.
[236] B. Schartel, P. Pötschke, U. Knoll, and M. Abdel-Goad. Fire behaviour of polyamide 6-multiwall carbon nanotube nanocomposites. European Polymer Journal, Volume 41, Issue 5, 2005, Pages 1061-1070.

[237] A. Fina, S. Bocchini, and G. Camino. Catalytic fire retardant nanocomposites. Polymer Degradation and Stability, Volume 93, Issue 9, 2008, Pages 1647-1655.

[238] X. Wang, E. N. Kalali, J.-T. Wan, and D.-Y. Wang. Carbon-family materials for flame retardant polymeric materials. Progress in Polymer Science, Volume 69, 2017, Pages 22-46.

[239] T. Kashiwagi, M. Mu, K. Winey, B. Cipriano, S. R. Raghavan, S. Pack, M. Rafailovich, Y. Yang, E. Grulke, J. Shields, R. Harris, and J. Douglas. Relation between the viscoelastic and flammability properties of polymer nanocomposites. Polymer, Volume 49, Issue 20, 2008, Pages 4358-4368.

[240] M. C. Costache, M. J. Heidecker, E. Manias, G. Camino, A. Frache, G. Beyer, R. K. Gupta, and C. A. Wilkie. The influence of carbon nanotubes, organically modified montmorillonites and layered double hydroxides on the thermal degradation and fire retardancy of polyethylene, ethylene-vinyl acetate copolymer and polystyrene. Polymer, Volume 48, Issue 22, 2007, Pages 6532-6545.

[241] J. Sandler, M. S. P. Shaffer, T. Prasse, W. Bauhofer, K. Schulte, and A. H. Windle. Development of a dispersion process for carbon nanotubes in an epoxy matrix and the resulting electrical properties. Polymer, Volume 40, Issue 21, 1999, Pages 5967-5971.

[242] S. U. Khan, J. R. Pothnis, and J.-K. Kim. Effects of carbon nanotube alignment on electrical and mechanical properties of epoxy nanocomposites. Composites Part A: Applied Science and Manufacturing, Volume 49, 2013, Pages 26-34.

[243] X. Song, S. Liu, Z. Gan, Q. Lv, H. Cao, and H. Yan. Controllable fabrication of carbon nanotube-polymer hybrid thin film for strain sensing. Microelectronic Engineering, Volume 86, Issue 11, 2009, Pages 2330-2333.

[244] S. M. Vemuru, R. Wahi, S. Nagarajaiah, and P. M. Ajayan. Strain sensing using a multiwalled carbon nanotube film. The Journal of Strain Analysis for Engineering Design, Volume 44, Issue 7, 2009, Pages 555-562.

[245] C.-L. Chen, E. Lopez, Y.-J. Jung, S. Müftü, S. Selvarasah, and M. R. Dokmeci. Mechanical and electrical evaluation of parylene- $C$ encapsulated carbon nanotube networks on a flexible substrate. Applied Physics Letters, Volume 93, Issue 9, 2008, Pages 1-3.

[246] K. A. Sierros, D. S. Hecht, D. A. Banerjee, N. J. Morris, L. Hu, G. C. Irvin, R. S. Lee, and D. R. Cairns. Durable transparent carbon nanotube films for flexible device components. Thin Solid Films, Volume 518, Issue 23, 2010, Pages 6977-6983.

[247] I. Kang, M. J. Schulz, J. H. Kim, V. Shanov, and D. Shi. A carbon nanotube strain sensor for structural health monitoring. Smart Materials and Structures, Volume 15, Issue 3, 2006, Pages 737-748.

[248] C. L. Kane, E. J. Mele, R. S. Lee, J. E. Fischer, P. Petit, H. Dai, A. Thess, R. E. Smalley, A. R. M. Verschueren, S. J. Tans, and C. Dekker. Temperature-dependent resistivity of single-wall carbon nanotubes. Europhysics Letters, Volume 41, Number 6, 1998, Pages 683-688. 